\title{
IT TAKES A VILLAGE TO SUSTAIN A VILLAGE: A SOCIAL IDENTITY PERSPECTIVE ON SUCCESSFUL COMMUNITY-BASED ENTERPRISE CREATION
}

\author{
CHRISTINA HERTEL ${ }^{1}$ \\ École Polytechnique Fédérale de Lausanne
}

SOPHIE BACQ

Indiana University

FRANK-MARTIN BELZ

Technical University of Munich

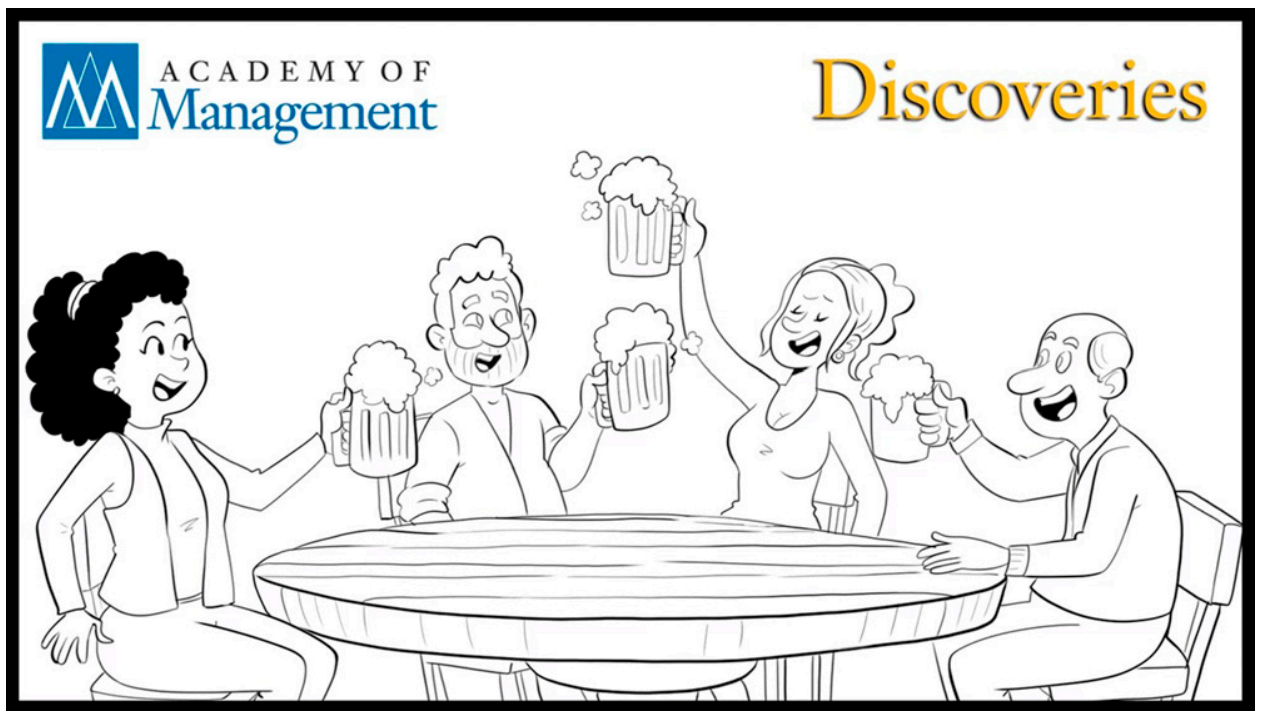

This article examines the powerful yet overlooked role of community-based enterprises (CBEs)-enterprises that are collectively established, owned, and controlled by the members of a local community, for which they aim to generate economic, social, and/or ecological benefits-in addressing a broad range of problems facing many rural communities around the globe. To understand why and how CBEs successfully come into existence, we conduct an exploratory case study of two community-based pubs founded in rural Bavaria, Germany, in the 2010s. Using abductive data analysis, we uncover several collective identity mechanisms that spur community mobilization and entrepreneurial action. Specifically, we find that, whereas an incumbent collective village identity lays the ground for successful CBE creation, an emergent enterprising community identity is critical to go beyond venture inception. Through identification with the entrepreneurial project, supporters develop a lasting commitment to it-reinforced over time through artifacts, rituals, and celebrations-which further feeds and sustains its implementation. Our study paves the way for future research on entrepreneurship, collective action, and identity in local communities.

[I]f rural communities are a hotspot of challenges for implementing the SDGs, they are also a hotspot for innovation and creative solutions.

- Jamison Ervin, UN Development Program

\section{INTRODUCTION}

Although sociodemographic changes, economic crises, and environmental challenges increasingly imperil the global population, these threats particularly exert pressure on rural communities who are

\footnotetext{
${ }^{1}$ Corresponding author.
} 
at risk of heightened instability and inequality (European Commission, 2014; UNDP, 2018). For rural communities in developing parts of the world, poverty remains the most pressing problem (IFAD, 2018), whereas a great number of rural communities in Europe and the United States suffer from eroded local infrastructure systems and a loss of employment opportunities-with detrimental effects on both their local economies and social lives (Bailey, 2012; Haugh, 2007; Kleinhans, 2017). Because of substantial cuts in funding for public services, many of these issues cannot be addressed by governments, let alone NGOs, and other philanthropic organizations. As a result, community-based action has become more important than ever (Dubb, 2016; Lumpkin, Bacq, \& Pidduck, 2018; van der Vegt, Essens, Wahlström, \& George, 2015), specifically when it comes to achieving the UN's Sustainable Development Goals (SDGs) (United Nations, 2015). In particular, this urgent call for action, which was adopted by all UN member states in 2015, acknowledges the role of local communities in eradicating poverty (SDG 1), ensuring reliable access to clean energy (SDG 7) and establishing sustainable consumption and production systems (SDG 12). Indeed, a growing number of local communities have become agents of their own change, by building different types of local organizations to tackle their problems (Daskalaki, Hjorth, \& Mair, 2015; Dubb, 2016; Rao \& Greve, 2018).

One such organizational form that has increasingly grown in prevalence is the community-based enterprise (CBE), a type of enterprise that is collectively established, owned, and controlled by the members of a local community, in which it is embedded and for which it aims to generate economic, social, and/ or ecological benefits (Hertel \& Belz, 2017; Peredo \& Chrisman, 2006). For example, in developing economies, a growing number of tourism, forestry, energy, and agricultural CBEs in rural areas harness community natural resources, generate jobs, and strengthen entire local economies, while also enhancing community cohesion and potentially contributing to the empowerment of previously underprivileged groups (Cieslik, 2016; Peredo \& Chrisman, 2006, 2017; Vega \& Keenan, 2016). In developed economies, CBEs have emerged in rural areas as mechanisms for reopening local businesses, such as supermarkets, pubs, bank branches, healthcare centers, and retirement homes. For instance, in the United Kingdom alone, we reestablished 350

\begin{tabular}{|l|}
\hline \multicolumn{1}{|c|}{ Author's voice: } \\
Social relevance of research?
\end{tabular}

shops as CBEs in rural areas, with a survival rate of more than 95 percent (Plunkett Foundation, 2017). These enterprises not only bring back jobs and local services but also strengthen the social life and the local economy of rural communities, thereby enhancing their resilience (Cabras \& Mount, 2017; Haugh, 2007; Somerville \& McElwee, 2011). Taken together, in this context, CBEs make important contributions to the achievement of SDG 11, striving for sustainable cities and communities. Yet, despite the growing prevalence and relevance of CBEs (Kleinhans, 2017; Peredo \& Chrisman, 2017), we still know little about why and how they emerge (Daskalaki et al., 2015), or why some communities seem to be more amenable to CBE creation than others (Peredo \& Chrisman, 2006). If CBEs are such a promising solution, then why do only some communities decide, and manage, to solve their problems by establishing these entities, whereas others facing similar conditions do not?

This study aims to shed light on the factors that enable and facilitate successful CBE creation-which we define as the setting up of enterprises that 1) are collectively established, owned, and governed by a large number of the people living in a community; 2) generate sufficient profit to sustain themselves; and 3) succeed in solving one or more economic, social, and/or ecological local problems as identified by the community. In this article, the term CBE creation comprises both the inception, i.e., the idea to establish a CBE and the decision to act on it, and the actual implementation of the idea. Our study focuses on the gestation stages of the CBE until its opening. We conducted an exploratory case study built on a comparative observation of two cases of communitybased pubs founded in rural Bavaria, Germany. Using abductive data analysis (Alvesson \& Kärreman, 2007), the social identity theory (Tajfel, 1974, 1982; Tajfel \& Turner, 1979) emerged as a useful theoretical lens to explain successful CBE creation. Building on the basic tenets of social identity theory, and combining identity-based explanations from the management, collective action, and social movement literatures, this article makes three distinct contributions to our understanding of CBE creation.

First, we provide a better understanding of the key prerequisites for successful CBE creation, namely, 1) collective agency, 2) willingness to invest private resources, and 3) lasting commitment. Second, we show that although the incumbent village identity and the locals'2 identification with their village enable successful CBE creation, they do not suffice for it. Successful CBE creation also requires certain mechanisms that act as catalysts to initiate and facilitate action. The four mechanisms we identify

\footnotetext{
${ }^{2}$ We use the terms "locals" and "villagers" interchangeably.
} 
are as follows: 1) perception of an identity threat, 2) comparison with similar groups, 3) perception of being challenged, and 4) perception of acknowledgement. Third, and maybe most relevantly, we reveal the importance of the apparition of a new group-the enterprising community-which we define as the group of people actively supporting CBE creation, and its associated emergent collective identity. We deliberately chose the term "emergent" to highlight that this new identity forms gradually and must be consolidated over time (Corley \& Gioia, 2004). We elucidate strategies which CBE initiators can use for explicitly reinforcing the emergence of this collective identity, thereby facilitating CBE creation.

Besides contributing to the CBE literature, our study shows how the phenomenon of CBE can serve as a promising setting for researchers interested in better understanding the interplay between local communities and organizations (Glynn, 2008; Howard-Grenville, Metzger, \& Meyer, 2013; Marquis \& Battilana, 2009; Marquis, Glynn, \& Davis, 2007; Marquis \& Lounsbury, 2007), and collective organizing in the face of external shocks (Rao \& Greve, 2018; Williams \& Shepherd, 2016). In particular, the identity-based explanation of successful CBE creation documented in our study answers calls for qualitative studies that explore how, and under what conditions, actors collectively mobilize resources and relationships to create effective solutions to their problems (Daskalaki et al., 2015; Marquis \& Lounsbury, 2007). Finally, our discovery lays the ground for further research on multilevel identity processes (Albert, Ashforth, \& Dutton, 2000; Ashforth, Rogers, \& Corley, 2011; Gioia, Patvardhan, Hamilton, \& Corley, 2013).

\section{THEORETICAL BACKGROUND}

\section{CBEs}

Definitions and demarcations. Based on a systematic literature review, Hertel and Belz (2017) define CBEs as enterprises that are collectively established, owned, and controlled by the members of a local community, in which they are embedded and for which they aim to generate economic, social, and/or ecological benefits. This definition consists of five elements, namely, 1) embeddedness, i.e., the entrenchment of a CBE into a local community's structures; 2) self-sustaining business activity, i.e., the production and commercialization of a product or service in an economically viable way; 3 ) multiplicity of goals, i.e., the goal to generate not only economic but also social and/or ecological benefits; 4) community orientation, i.e., the goal of generating benefits for the community as a whole, and not only for specific individuals; and 5) collective establishment, ownership, and control, i.e., the community members are the main actors in enterprise creation and governance, and hold most of the shares in the enterprise.

These five definitional elements help distinguish CBEs from related yet distinct organizational forms, such as cooperatives and social enterprises. Both CBEs and cooperatives are self-sustaining ventures with collective ownership and governance structures (criteria 2 and 5). Although some CBEs might be legally structured as cooperatives, conventional cooperatives that are not CBEs are often driven by mere economic motives and restrict their benefits to their members instead of advancing the interests of the broader local community (at odds with criteria 3 and 4).

Scholars have also pointed to the importance of a community basis for social enterprises (Lumpkin et al., 2018). Although some social enterprises may also be self-sustaining and embedded in a community for which they aim to generate social value (criteria 1, 2, 3, and 4), they are substantially distinct from CBEs because they are not collectively established, owned, and governed (at odds with criterion 5). Thus, despite similarities with other organizational arrangements, CBEs are substantially distinct in that they often emerge in the face of some sort of crisis (Johnstone \& Lionais, 2004), aim at benefiting the community as a whole (not just the members of the organization), and depend on the involvement of a large number of people inside and outside the community who contribute human, financial, natural, and social resources (Vestrum \& Rasmussen, 2013). As a result, CBEs require separate exploration and explanation (Haugh, 2007; Hertel \& Belz, 2017; Peredo \& Chrisman, 2006).

CBE creation. Thus far, most of the research on this topic has focused on describing CBEs and on exploring their potential to tackle local problems, but has neglected the process by which they are created. Only a handful of studies provide empirical descriptions of the entire CBE creation process (Haugh, 2007; Valchovska \& Watts, 2016) or specific aspects of this process, such as embedding (Vestrum, 2014), resource mobilization (Vestrum, 2016), or legitimacy building (Vestrum, Rasmussen, \& Carter, 2017). Haugh (2007) developed a six-stage process model of CBE creation comprising 1) opportunity identification, 2) idea articulation, 3) idea ownership, 4) stakeholder mobilization, 5) opportunity exploitation, and 6) stakeholder reflection. Although this model is a valuable starting point that provides an objective description of how the venture creation process unfolds over time, neither it nor any other existing studies provide an understanding of the dynamics that trigger and fuel this process.

Broadly, researchers agree that CBEs will emerge in contexts of instability and flux (Bailey, 2012; Daskalaki et al., 2015; Kleinhans, 2017). Peredo and 
Chrisman (2006) theoretically derived four necessary factors for their emergence, namely, 1) the presence of multifaceted local problems, 2) a tradition of collective action, 3) a deposit of social capital and networks, and 4) a medium community size. Acknowledging that these factors constitute only a preliminary attempt to explain typical components of successful CBE creation, the authors stressed that further research is required to explore why some communities are more conducive to CBE creation than others. So far, subsequent work has mainly focused on verifying the factors Peredo and Chrisman identified (e.g., Handy, Cnaan, Bhat, \& Meijs, 2011; Valchovska \& Watts, 2016), but has not dug deeper into the enabling factors of successful CBE creation. A handful of articles have mentioned that a sense of shared identity might play a role (e.g., Dana \& Light, 2011; Peredo \& Chrisman, 2006; Vestrum, 2014). However, no research has specifically explored the role of identity and related concepts in CBE creation. During the analysis of our data, identity and identification emerged as key themes, and employing social identity theory helped us to explain successful CBE creation. In the following section, we briefly introduce social identity theory and its application in extant research.

\section{Identity and Identification}

Across different scholarly fields, social identity theory (Tajfel, 1974, 1982; Tajfel \& Turner, 1979) has become a key theoretical perspective for explaining the behaviors of individuals. Social identity theory assumes that individuals break down their social environment into groups (Tajfel \& Turner, 1979) and that an individual's social identity is then derived through self-categorization, i.e., the identification with certain in-groups, and social comparison, i.e., the comparison with other out-groups (Hogg \& Abrams, 1988). Identification helps individuals locate themselves in their social environments, serves as a frame for interpreting information, and steers motivations and behaviors, as individuals tend to act in ways that are consistent with the prototypical behavior associated with their in-groups (Hogg, Terry, \& White, 1995; Stets \& Burke, 2000). This prototypical behavior is rooted in a collective group identity, which is understood as the group members' shared perceptions of the values, practices, and culture that define "who they are as a group," and what differentiates them from others (Albert et al., 2000; Albert \& Whetten, 1985; Bartel \& Wiesenfeld, 2013). Naturally, individuals identify with multiple groups at the same time, and these identities are organized hierarchically (Hogg et al., 1995). The more salient an identity is-meaning, the further up in the hierarchy it is-the more action relevant it becomes.

Identity and identification have become important theoretical concepts in the organizational and management research (Albert et al., 2000; Ashforth, Harrison, \& Corley, 2008; Gioia et al., 2013) and, more recently, their application has also gained traction in entrepreneurship research (Fauchart \& Gruber, 2011; Gruber \& MacMillan, 2017; Navis \& Glynn, 2011). Over the past two decades, identity has also proven to be useful in explaining collective action and social movement dynamics (Snow \& McAdam, 2000; Stryker, Owens, \& White, 2000). Against this backdrop, it comes as a surprise that social identity has not yet been used to explain CBE creation. The findings of this study, pointing to the use of social identity theory to understand and explain the enabling factors of successful CBE creation, address this shortcoming.

\section{RESEARCH SETTING}

The phenomenon of CBE creation is not new. Yet, over the past two decades, the idea of the CBE as an effective and highly adaptable mechanism for local development has gained in popularity worldwide (Bailey, 2012; Peredo \& Chrisman, 2017). CBEs have emerged in different contexts and to address the specific needs of local communities around the world. Thus far, most of the literature has focused on CBEs in developing contexts characterized by poverty and inequality (Hertel \& Belz, 2017). Despite calls to explore cases in developed settings (Daskalaki et al. 2015; Peredo \& Chrisman, 2006), only a handful of authors have done so (e.g., Haugh, 2007; Valchovska \& Watts, 2016; Vestrum, 2014). This a major shortcoming, as a growing number of CBEs are being established in rural regions in the United States and Europe (Bailey, 2012; Peredo \& Chrisman, 2017), where many villages struggle with economic decline, the loss of employment opportunities, migration, and a loss of local infrastructure and important local businesses, such as pubs, stores, bank branches, post offices, childcare facilities, and retirement homes (Plunkett Foundation, 2017; Somerville \& McElwee, 2011). Recent economic crises have forced many governments to withdraw services and cut budgets, leaving them unable to solve the problems for the villages, and hence aggravating problems in these regions (Haugh, 2007; Kleinhans, 2017).

At the first glance, the loss of pubs may not seem like a serious issue. However, these local businesses play a significant role in rural communities. Although some may regard pubs as places where people "merely" eat, drink, play cards, or watch 
sports, all of these activities are mostly carried out with others and are an important element of many villagers' social lives (Cabras \& Reggiani, 2010). Besides contributing to the local economy, pubs are pivotal for strengthening community cohesion and generating social capital (Maye, Ilbery, \& Kneafsey, 2005; Mount \& Cabras, 2016). Particularly in rural regions, pubs have been found to trigger the emergence of new community initiatives and enhance social engagement by providing important venues for discussing collective concerns and channeling passions, thereby enhancing the general resilience of rural communities in the face of shocks and crises (Besser, 2009; Cabras \& Mount, 2017). Moreover, they represent an important aspect of local culture and act as unique manifestations of local traditions that vanish with their closure (Hopfinger, Kohnle, \& Wätzold, 2013). Overall, pubs play a critical role in villages and their loss leaves "black holes," whose effects go far beyond the mere loss of a local business (Cabras \& Mount, 2017: 493). As such, it is not surprising that pub loss and the significance of its negative effects have garnered increasing interest in recent years from scholars from different fields, such as regional planning, sociology, and entrepreneurship (Cabras \& Mount, 2017; Cabras \& Reggiani, 2010; Lincoln, 2006; Maye et al., 2005).

\section{Altenau and Vorderburg-Two Rural Villages in Bavaria}

In this article, we explore two cases of communitybased pubs established in rural Bavaria, Germany. The federal state of Bavaria constitutes a promising research context: although it is the second strongest state economy in Germany, many rural communities have lost important local businesses, depriving them of access to important services and fueling migration of the populace to metropolitan areas. In 2016, more than 150 Bavarian municipalities had already lost all local supply facilities (i.e., supermarkets, grocery stores, bakeries, butcher's stores, other food, and/or supply stores), whereas many more had lost large parts of their local supply infrastructure (Stern, 2018). A more recent study even identified $604 \mathrm{mu}-$ nicipalities (nearly one-third of all Bavarian municipalities) without any local shop (Bayern SPD Landtagsfraktion, 2016). In some regions, the number of local retail facilities decreased by more than 25 percent between 2005 and 2016 (Kühne, Seibold, \& Zierer, 2016). In more than 750 municipalities, villages have lost their last pub or restaurant (Hopfinger et al., 2013). Bavaria is a region that is known worldwide for its pub culture, and a comprehensive study of the issue of pub loss in Bavaria stresses that "where the pub dies, the village dies" (Hopfinger et al., 2013: 5). Because of budget cuts, most municipalities cannot assume responsibility for such problems (Kleinhans, 2017). These factors make community-based pubs in Bavaria an apt and representative research setting for the study of $\mathrm{CBE}$ creation in a developed setting.

The CBEs we studied for this article were established in Altenau and Vorderburg, two small villages in Bavaria. Altenau, a village of about 630 inhabitants, lies in the south of Bavaria and is part of the municipality of Saulgrub, which comprised three villages. With its proximity to the castles of King Ludwig II, and its lakes and mountains, this region attracts tourists from all over the world. The village itself is relatively unknown to tourists, offering only a few private guest rooms. Many of the old houses in the village used to be farms; some farms are still in operation today. Vorderburg is a small village of about 550 inhabitants located in the southwest of Bavaria. It belongs to the municipality of Rettenberg, which also comprised three villages. Situated close to the mountains, recreational offers such as hiking, skiing, and cycling make the area an attractive destination for tourists. Although the village itself is small, it still attracts many visitors, as a popular cycling route passes through its center. Like in Altenau, some villagers still operate farms or handicraft enterprises. Hence, the villages have similar sociodemographic structures and their village centers consist of a church, the former school, the fire brigade's house, and the-former-pub.

Both villages draw on a long history of collective action, reflected in numerous associations, some of which date back to the 19th century (e.g., voluntary fire brigade, rifle association, church choir, traditional costume society, and folk music band). Indeed, there is no less than 16 associations in Altenau and nine associations in Vorderburg. They play an important role in the lives of the locals, their daily activities, and annual festivities, and generate a sense of pride. Hence, extensive participation in the village associations is honored in these two villages. More recently, locals from both villages engaged in collective action to renovate community buildings, namely, the church in Altenau and the fire brigade's house in Vorderburg.

Both local communities faced similar problems, which they eventually solved through the creation of a CBE. In both villages, the local pub had always played an important role as a central meeting point for the villagers. Parts of the pubs were large village halls, which served as headquarters for local associations and provided space for public and private events. However, despite the pubs' significance to their communities, their owners were confronted with an increasingly serious challenge: the buildings had grown old and needed extensive renovations, which 
made them less attractive. As a result, the businesses were not profitable for their tenants anymore and, over the years, many tenants came and left. However, the required renovation would have entailed a massive increase in the monthly rent paid by the tenants, making it impossible for them to run their businesses profitably under the given circumstances.

In Altenau, the owners of the building, an elderly couple from the village, decided not to search for another tenant after the last one left in 2001. Villagers' dissatisfaction grew, but even with governmental support, they could not find a feasible solution. In Vorderburg, the situation was similar. The owner, a local brewery, decided to close the pub and sell the building, after the last tenant quit in 2015. For villages such as Altenau and Vorderburg, characterized by their strong and vivid fabric of the community, the loss of the village pub entailed various detrimental effects, far beyond the loss of a place to drink and dine: with the closure of their pub, both communities were deprived of their central meeting point and the headquarters of many of their associations. Although some associations managed to find alternative places, this led to a segregation that prohibited interaction among people from different associations. Other associations, however, were closed altogether as the pub was critical for them not only as a meeting point but also as a platform for their performances. In Altenau, for instance, the theater association, an association with a long history in the village, closed and was only reestablished after the new CBE opened in 2016. Taken together, these dynamics led to a general sense of dissatisfaction among villagers, as reflected in the following quotes:

I was 17 or 18 when I was allowed to go to the regulars' table in the pub for the first time. And that was where you met your friends. That was where you discussed local politics, and also where you asked others about what was happening in their lives. Altenau-VF

That's just what you should have in any village center: a church, a school and a pub-and we had been missing that pub for ten years. And with the loss of the pub, we had also lost a part of our tradition. Cohesion suffers from that; it's just a necessary puzzle piece in a village like ours. Altenau-I1

The problem was that the pub closed and... Well, that's it. We didn't have a place to go anymore. [...] Sitting somewhere talking to all the othersthat wasn't possible anymore. Vorderburg-I3

And I think it is fundamentally important that I have a pub-not for getting drunk, but to have a meeting point so that everybody, young and old, can get together. That's actually the most important thing for us, the most important, yeah, because, the experience older people have-where should our youth get that from? Vorderburg-I5

\section{The CBEs in Altenau and Vorderburg}

In Altenau, two villagers came up with the idea of reestablishing the pub as a CBE in 2013. Within only one week, a core team of villagers raised $€ 384,000$ by selling shares to more than 170 villagers. In addition, they raised about $€ 316,000$ from the municipality and local businesses to implement their plans. Over a 16 -month renovation process, the villagers additionally invested more than 22,000 hours of voluntary labor. By engaging the broader community in their endeavors, the core team managed to plan, and later implement, the entire project with hardly any governmental support. Eventually, more than 200 villagers had contributed to the project in some way, allowing them to build a pub worth nearly $€ 2,000,000$. The new community-based pub opened in 2015. This community-based pub soon became the new heart of the village and revitalized its social and associative life. In addition, the collective achievement developed strong social cohesion among the community members, set the ground for various other community projects, and attracted many tourists.

Similarly, in Vorderburg, two villagers decided to reestablish the pub as a CBE soon after the last tenant had announced to leave. A core team of nine individuals took the lead and raised $€ 204,000$ through selling shares to villagers and $€ 230,000$ in grants and subsidies from local businesses and the municipality. Over 19 months, the villagers put in more than 21,000 hours of voluntary labor in the creation of the CBE. Like in Altenau, a very large part of the local population contributed to the planning and implementation by bringing in their expertise (e.g., in architecture and in construction) or donating materials. The community-based pub and village hall reopened in 2017 and immediately became the new center of community life. As in Altenau, this collective achievement improved the social life in the village and spurred many follow-up projects that benefitted the community, such as the creation of a small village shop and a bank branch.

\section{METHODOLOGY}

\section{Research Design}

Because of the lack of extant research on successful CBE creation, we adopted an exploratory case study-the preferred method for investigating 
novel, complex phenomena within real-life contexts (Yin, 2013)-built on a set of two comparative cases. Initially, we planned to rely primarily on semistructured interviews. However, after our first round of data collection, we encountered three different "breakdowns"- -unexpected misalignments between our theoretical assumptions and empirical impressions (Alvesson \& Kärreman, 2007: 1,266)—that required an adjustment of the research design. Accordingly, we decided to use more ethnographic data collection approaches, such as participant and nonparticipant observation, which have proven useful for resolving breakdowns encountered during the research process (Agar, 1986; Mantere \& Ketokivi, 2013). Ethnographic data collection methods are particularly well suited for phenomena rooted in local cultures and identities, as they allow the researcher to immerse in, and holistically understand, local cultures and identities (Hammersley \& Atkinson, 2007; Mantere \& Ketokivi, 2013; Poteete, Janssen, \& Ostrom, 2010).

\section{Sampling Procedure}

We searched for revelatory cases (Yin, 2013) by adopting a purposeful sampling strategy (Patton, 1990). An expert, who worked as a CBE consultant for more than a decade, helped us to identify suitable cases. We first selected Altenau, as it offered access to unique data, including extensive video footage of the CBE creation process. During the data collection process there, we learned about Vorderburg, where we had the opportunity to track elements of their CBE creation process as it unfolded. We soon found that although the cases in Altenau and Vorderburg were similar in various respects, they differed in central aspects and,
Author's voice:

How did you get access to your data?

therefore, were an ideal set of complementary, revelatory cases for our research goal (Yin, 2013).

\section{Data Collection}

In our first round of data collection and analysis, we collected data by means of interviews. Following the breakdowns (see Data Analysis), we accordingly engaged in additional rounds of data collection using ethnographic methods, including semi-structured interviews (partially supported by visual methods), nonparticipant and participant observations, visual data (photos and videos), and both internal and external secondary data (see Table 1). Overall, the first author spent more than 125 hours in Altenau, split across three visits, and more than 450 hours in Vorderburg, split across four visits. This helped us gain villagers' trust and acceptance within the communities, which was crucial for understanding the dynamics of their CBE creation processes, and comprehending the relations between the different actors, as well as their backgrounds and resultant motivations. As we draw from unique data sources for each of the two cases, in the following paragraph, we briefly expound on the specific data collection process for each of our two cases.

Data collection in Altenau. We began our data collection in Altenau in March 2016. Their CBE creation process started in 2013, and their CBE opened in 2015. Although we could not follow the creation process in real time, we had access to video footage, as a local television station had documented

TABLE 1

Overview of the Data

\begin{tabular}{|c|c|c|c|}
\hline Data Source & & Altenau & Vorderburg \\
\hline \multirow[t]{2}{*}{ Primary data } & Interviews (I) & 7 interviews with 6 individuals (288 minutes) & 7 interviews with 7 individuals (265 minutes) \\
\hline & Field notes (FN) & $\begin{array}{l}19 \text { pages of field notes from nonparticipant } \\
\text { observations made during } 3 \text { visits (125 } \\
\text { hours on site) }\end{array}$ & $\begin{array}{l}31 \text { pages of field notes from nonparticipant and } \\
\text { participant observations made during } 4 \text { visits } \\
\text { (450 hours on site) }\end{array}$ \\
\hline \multirow[t]{3}{*}{ Secondary data } & Video footage (VF) & $\begin{array}{l}51 \text { episodes ( } 2-7 \text { min each) of a TV } \\
\text { documentary following the CBE } \\
\text { creation process in real time; } 31 \\
\text { pages of summaries and transcriptions } \\
\text { of key quotes }\end{array}$ & $\mathrm{n} / \mathrm{a}$ \\
\hline & Internal documents (ID) & $\begin{array}{l}52 \text { pages of internal documents (legal } \\
\text { documents, plans and organigrams, } \\
\text { internal documentation of the process) }\end{array}$ & $\begin{array}{l}42 \text { pages of internal documents (legal documents, } \\
\text { plans, detailed time sheet documenting all } \\
\text { involved individuals and their activities, } \\
\text { further internal documentation of the process) }\end{array}$ \\
\hline & External documents (ED) & $\begin{array}{l}16 \text { pages of archival documents } \\
\text { (newspaper articles, press releases, } \\
\text { and transcripts of TV reports) }\end{array}$ & $\begin{array}{l}62 \text { pages of archival documents (newspaper } \\
\text { articles, press releases, and transcripts of } \\
\text { TV and radio reports) }\end{array}$ \\
\hline
\end{tabular}


the creation process over 17 months, resulting in 264 minutes of video footage divided across 51 short episodes (see: https:/www.br.de/themen/bayern/ inhalt/ein-dorf-wird-wirt/index.html). Before our initial interviews, we watched all episodes, made detailed notes, and transcribed revealing quotes. These notes served as a basis for our first round of semi-structured interviews. Using snowball sampling (Denzin \& Lincoln, 2000), we then proceeded to conduct seven semi-structured interviews with the CBE initiators and other core team members, then with other supporters, continuing to find new interview subjects until we felt that new interviews were not yielding novel information. The interviews lasted between 35 and 95 minutes each, were audio-recorded, and then transcribed verbatim. We conducted all interviews directly at the communitybased pub, as we observed during the first interviews that this environment stimulated the interviewees' emotions, helping them recall events and details. During her three site visits, the first author also led various informal conversations, during which she took field notes that she later digitized. Finally, the CBE team granted us access to their internal archive of articles published on their project in online and offline media outlets, as well as official documents, such as communication materials, business plans, and legal documents.

Data collection in Vorderburg. In Vorderburg, the CBE creation process was initiated in 2016 and their community-based pub opened in June 2017. We began our data collection in January 2017 and were thus able to document several months of the creation process directly as it unfolded. To make maximum use of this research opportunity, the lead author visited the community four times for several days in monthly intervals and participated in multiple important CBE-related meetings and events. Adopting the same respondent sampling strategy as in Altenau, she conducted seven semi-structured interviews, lasting 25-85 minutes. During each of her visits, the first author shadowed CBE supporters on the construction site where parts of the old pub were being renovated and annexes were being built, and actively participated in the construction work. In addition, she accompanied lead actors in their everyday lives to get a better understanding of their ways of life, recording her observations in a diary. Later, she attended the inaugural events for the CBE that extended over several days and included holistic, collective reviews of the entire process. She recorded and transcribed the speeches held during these festivities, which turned out to be pivotal data sources. We triangulated our primary data with secondary data from public and internal sources. Most importantly, we built on the internal time sheet the core team used to track each task that was performed by specific individuals throughout the whole process.

\section{Data Analysis}

We used an abductive data analysis approach to provide theoretical explanations for novel phenomena (Alvesson \& Kärreman, 2007). Abduction, as a form of scientific reasoning, is based on surprising, or puzzling, empirical material (Hanson, 1958), which is then, in a methodological rigorous process, analyzed against the background of a variety of theoretical lenses (Alvesson \& Kärreman, 2007). In the following sections, we elaborate on each analytic step we engaged in.

Case narratives. As a first step, we followed a narrative strategy, aiming to create a condensed, detailed story of the two CBE creation processes (Langley, 1999). To do so, we used MAXQDA to assign codes and time marks to our data. Following Yin (2013), we first did within-case analyses before proceeding to a between-case analysis. We created a document in the chronological order for each case and used different types of data displays (Miles, Huberman, \& Saldana, 2014). The resultant case narratives constituted the basis for our subsequent analysis steps (Langley, 1999).

Breakdowns. The case narratives yielded three breakdowns that were not in line with existing theory and could not be explained by the empirical evidence we had collected at first (Alvesson \& Kärreman, 2007; Mantere \& Ketokivi, 2013). First, although the characteristics of the villages and the underlying problem were very similar in both cases, it took 12 years after the closure of the pub in Altenau for CBE creation to commence. In Vorderburg, on the other hand, the process started directly after the past owner had decided to sell the building. This left us with the following question: How can we explain that it took 12 years to initiate CBE creation in Altenau, whereas the community in Vorderburg immediately resorted to creating a CBE?

Second, in Vorderburg, governmental subsidies initially provided a central building block in the financial concept of the CBE, but most of these external financial sources were cancelled later because of changes in regulations and unrealistic requirements. What puzzled us was the fact that this withdrawal of external support did not impede CBE creation but instead motivated the villagers to find solutions for a more ambitious CBE. This led to the question: How can we explain that a lack, or withdrawal, of governmental support fueled successful CBE creation?

Third, our data contained statements that sounded almost unbelievable or counterintuitive. For example, respondents repeatedly highlighted how amazed they had been by the inexhaustible and evergrowing support for the CBE. In both cases, more than 200 people (in villages counting 500-600 
inhabitants) actively participated in CBE creation, investing money, natural resources, time, and expertise into the project. Although the processes were lengthy (16 months in Altenau and 19 months in Vorderburg) and strenuous, the number of active supporters steadily increased-instead of decreasingover time, which is what we would have expected based on our experience from prior research projects, and findings in the social movements and collective action literatures (e.g., Klandermans \& Oegema, 1987; Stryker, 2000). Therefore, the third question that confronted us was the following, How can we explain that both cases managed to sustain, and even increase, commitment over such long periods of time?

When surprising findings call for an explanation, abductive reasoning is appropriate (Timmermans \& Tavory, 2012). With our research objective and the three breakdowns in mind, we engaged in several further rounds of coding and data collection. In our first round of open coding, we kept as close to the respondents' voices as possible. When we condensed the long list of open codes into first-order codes, we became aware of the respondents' extensive use of the terms "identify" and "identification." We also found that, in both villages, CBE actors had strong feelings of attachment to their village, equated themselves with their village, and clearly differentiated their village from
Author's voice:

Was there anything that surprised you about the findings? other villages. We realized that identification could be the key to explaining the breakdowns we encountered and used it as a starting point for our dialogue with the data, but remained open to being challenged by the data (Mantere \& Ketokivi, 2013). As we used more ethnographic methods (Hammersley \& Atkinson, 2007; Poteete et al., 2010), focusing on immersing ourselves in the local culture, traditions, and history through nonparticipant, and participant observation as well as informal conversations, we gradually gained an understanding of what drives the locals' identification with their village and its effect on successful CBE creation. During our iterative analysis steps, the development and reinforcement of an emergent collective identity as an enterprising community additionally revealed itself as an enabler for successful CBE creation.

\section{FINDINGS}

Analysis of our empirical evidence allowed us to develop a model for explaining successful CBE

FIGURE 1

An Identity-Based Explanation of Successful Community Enterprise Creation (View Animation)

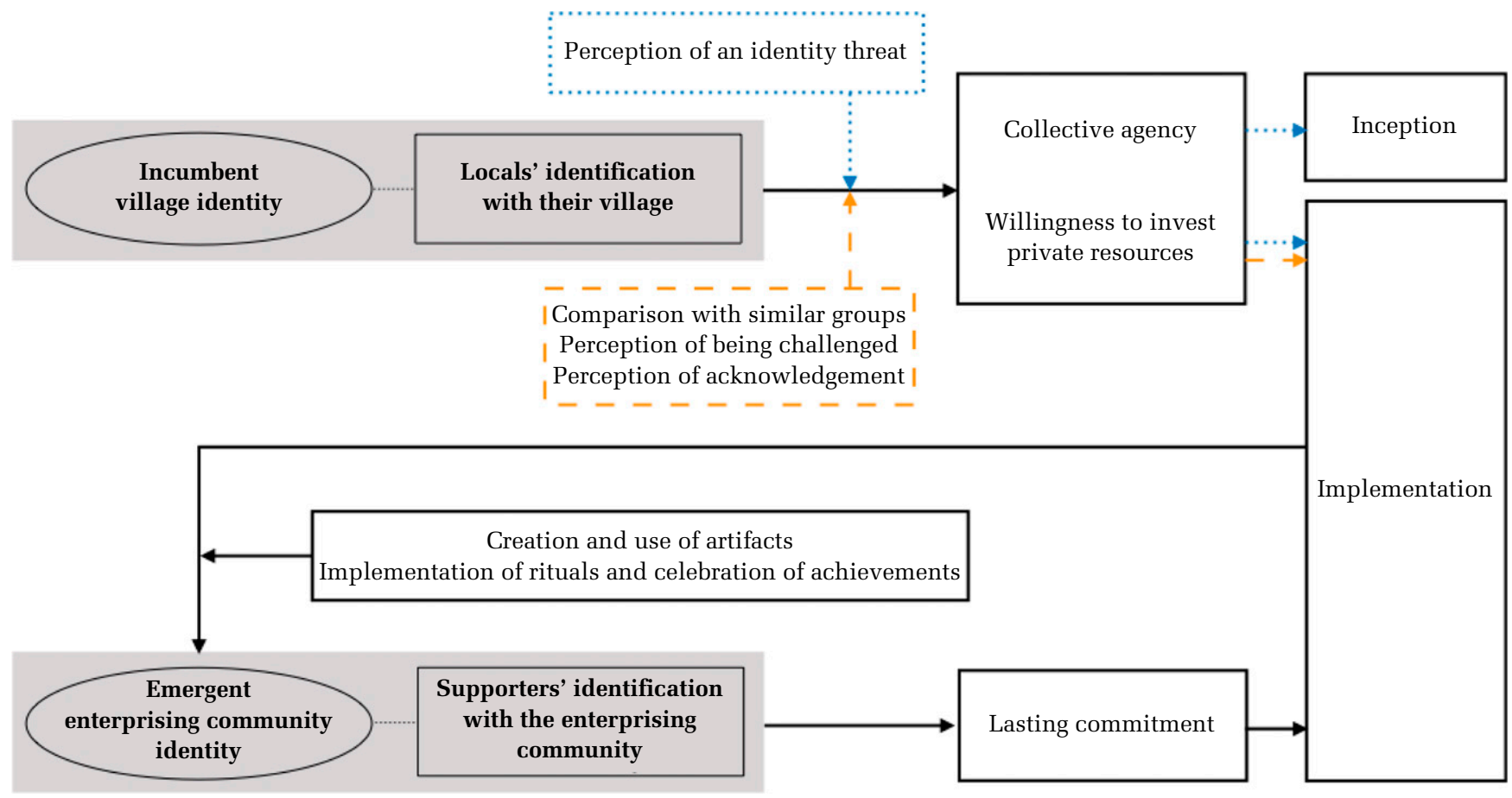

Note: Although "Perception of an identity threat" is the only mechanism that has an effect on both inception and implementation (indicated by blue, dotted lines), the other three mechanisms only affect the implementation of the CBE plans (indicated by orange, dashed lines). 
FIGURE 2

\section{Evidence for the Key Prerequisites in Our Cases}

\section{ALTENAU}

Collective agency. CBE creation started in 2012, when the owners decided to sell the building to the highest bidder. When two villagers heard that several external investors had already declared their interest, they realized that this was their last chance to save the pub. The two soon came up with a vision: "But... what if we did it collectively?" (Altenau-I3). Together, they developed an initial vision and realized that implementing their idea would require a strong team willing to take on responsibility, which is why they assembled a team of ten members.

Willingness to invest. Over the next few weeks, the core team worked on developing a broad concept, based on which they convinced eight villagers to invest $€ 50,000$ each. This left $€ 94,000$ for the rest of the community to cover in the form of $€ 1,000$ shares in the enterprise. In January 2013, the core team organized an event with the aim of evaluating villagers' willingness to participate. The hall was "full to bursting" (Altenau-I2) and, within one week, the team had raised more money than expected.

Lasting commitment. Successful mobilization of a large part of the community only marked the start of a lengthy planning and implementation phase. In April 2015, the community started with the renovation of the entire building. Over 16 months, between 20 and 50 people voluntarily helped on the construction site every weekend. The level of support exceeded all expectations and the team was able to continuously extend their plans. Although the implementation process took 16 months, commitment to the project did not decrease. On the contrary, people who had been skeptical in the beginning joined in at later stages. Overall, more than 250 people supported the project by investing money, helping with planning, donating and/or collecting building materials, helping on the construction site, or providing food for those workers. creation (Figure 1), which we expound on in the following section.

\section{Key Prerequisites}

Based on our case narratives, we identified three prerequisites for successful CBE creation. Figure 2 provides accounts of these prerequisites in our two cases.

Collective agency. Collective agency can be conceptualized as people's shared beliefs in their

\section{VORDERBURG}

Collective agency. When a local contractor received information that the building was about to be sold to an external construction company, he immediately called a friend, who was very well known for his involvement and leadership in various village associations, to tell him about this "catastrophe" (Vorderburg-I5) and ask for his help in preventing it. For the two, it seemed instantly clear that this issue had to be solved collectively. They decided they would need a strong team and convinced other seven highly village-committed individuals to join them and officially take on process ownership.

Willingness to invest. The team concluded that they needed $€ 200,000$ from the community on top of the governmental subsidies they had acquired for this project. A community information event on the proposed CBE in late 2015 attracted more than 200 people. One week later, the team had collected $€ 204,000$ by selling shares. When most of the community's governmental subsidies were cancelled due to changes in regulations, the team almost canceled their plans. However, the rest of community came up with an idea to mitigate this setback, collecting over 200 cubic meters of wood, which was partially used for the construction and partially sold to benefit the venture.

Lasting commitment. The construction process started in late 2015. From then on, more than 25 villagers worked on the construction site every weekend for over 19 months. Everyone in the village was invited to contribute in his or her own way: While local experts led teams of volunteer workers on the construction site, women were responsible for painting, the elderly took care of airing out the facility during the week, and the entire community collectively nailed the traditional shingles to the façade. Although the information event had already indicated a high level of support, the core team repeatedly expressed their surprise about the enduring commitment of their supporters. Despite the length of the process, participation increased over time and villagers who had been skeptical initially joined the project at later stages.

collective capacity to produce an outcome that cannot be accomplished by an individual (Bandura, 2000). Although many local communities face economic, social, and/or ecological problems of some kind, most remain inactive in response to them. CBE creation is only triggered if the members of a community decide to take their fate into their own hands and, instead of waiting for a top-down solution, collectively assume responsibility for tackling the problem. The following quotes illustrate the villagers' sense of collective agency in both the cases: 
We needed to take that into our own hands, that was clear. [...] We are a small, sworn village community, and with that cohesion, it's possible to accomplish projects like that! Altenau-I2

It was pretty obvious that we had to do this collectively. Vorderburg-I1

Adrian immediately called me and said, "Steffen, the pub is about to be sold. We need to do something-this is a catastrophe for us!" Vorderburg-I3

Willingness to invest private resources. Although collective agency sets the ground for CBE creation, a CBE can only be established if a critical mass of villagers commits to investing their private resources toward the common cause. Our narratives showed that the creation of a CBE requires different types of financial, natural, human, and social capital, invested by different people at different points in time. The main financial investment is covered in the early phases of the process, mostly through the sale of shares in the enterprise and raising of external subsidies. In both villages, the CBE initiators realized that, if their projects were to be successful in the long run, ownership had to lie with the community. Interestingly, they did not encounter any challenges when it came to raising money from the community, even though no investors could expect any significant returns on their investments. On the contrary, in both cases, community investments exceeded expectations, allowing to expand initial plans. The following quotes depict the core team members' surprise in the face of their unexpected mobilization success:

They had to come with their contributions to my house. Seriously, I think I have never had to drink so much schnapps in my entire life before-at least not within ten days! (...) It was beyond belief! The degree of enthusiasm people came with and [said]: "I participate with $€$ 1,000," "I put in 5,000€"-from people we hadn't expected anything from! Altenau-I5

When more than 200 people showed up, we already knew: there is a high interest in saving the pub. (...) Then we told them that, with the shares, they had one week. It was a really thrilling week. (...) And suddenly, we had sold 204 shares-204 shares within one week! Vorderburg-I1

Lasting commitment. Although investing financial resources in a CBE is crucial for its inception, this is only a one-time act that does not entail further commitment. Our case narratives, however, clearly show the importance of an extensive investment of time, expertise, and hard work to implement CBE plans. In both cases, the profitability of operations is attributable to villagers' high investments of human capital (about 22,000 hours of voluntary labor in Altenau and 21,000 hours in Vorderburg). Echoing debates in the collective action and social movements literatures (e.g., Klandermans \& Oegema, 1987; Stryker, 2000), we find that the final key prerequisite for successful CBE creation is the lasting commitment of a large group of supporters from the broader community, as the following interview quotes illustrate:

[...] we managed to do much more with the same budget than we had initially planned. That was really amazing. We saved so much money because of all this continuous voluntary work, it was simply amazing! Altenau-I3

We often thought that the motivation would decrease over time. This might have happened with some people for two or three weeks-and then everybody was back! Vorderburg-3

\section{Enabler I: Incumbent Village Identity and Locals' Identification with Their Village}

In both villages, we found evidence of a strong collective village identity with deep traditional and cultural roots. The folklore music association, tractor club, and traditional costumes society are three examples of large and powerful village associations whose long-established activities embody the values, practices, and culture that form the village identity, and allow the locals to enact their collective identity. Our data also show this strong collective sense of identity by locals' expression of strong opinions on what it means to be a villager and how one such ought to behave. Table 2 provides empirical evidence of the locals' identification with their village, as well as differentiation from other villages' identities (Tajfel \& Turner, 1979).

Our analysis further revealed that the locals' strong identification with their village functioned as an enabler of successful CBE creation. In particular, we observed that identification seemed to enhance collective agency and the locals' willingness to invest their private resources toward a common cause. In each case, we identified two villagers with a long history of involvement in community activities as initiators of CBE creation. These initiators' strong identification with their village led them to perceive village problems as their personal problems and to 
TABLE 2

Evidence for the High-Level Identification with the Villages

\begin{tabular}{|c|c|c|}
\hline & Exemplary Quote from Altenau & Exemplary Quote from Vorderburg \\
\hline $\begin{array}{l}\text { Identification with the } \\
\text { village }\end{array}$ & $\begin{array}{l}\text { I identify with the village } 100 \% \text { because there's this } \\
\text { cohesion, because it's where I come from, it's the } \\
\text { center of my and my family's life. Altenau-VF2 } \\
\text { I couldn't imagine moving away. If some princess } \\
\text { from Schloss Linderhof had called me, I would have } \\
\text { replied: 'Great, but you need to come to Altenau!' } \\
\text { My wife is from here and I could never have } \\
\text { imagined moving even to the next village. That } \\
\text { would have been impossible. I was born here and I } \\
\text { know that I will die here. Altenau-I7 }\end{array}$ & $\begin{array}{l}\text { I don't know, it's the cohesion. People absolutely, } \\
\text { absolutely identify with the village here. Vorderburg- } \\
\text { I2 } \\
\text { Well, you just have this emotional attachment to this } \\
\text { village here. . . attachment, yes. Not only as an } \\
\text { individual but with the entire family - it's pretty } \\
\text { amazing. . Vorderburg-I5 }\end{array}$ \\
\hline $\begin{array}{l}\text { Differentiation from other } \\
\text { villages }\end{array}$ & $\begin{array}{l}\text { Altenau is, when it comes to life in the village, an } \\
\text { independent place. Of course, we could have gone } \\
\text { to Saulgrub, they would have let us use their village } \\
\text { hall - but you just wouldn't have the same } \\
\text { identification there! Altenau-I7 }\end{array}$ & $\begin{array}{l}\text { No, not a real local, I'm a border crosser. I live about } 100 \\
\text { meter on the other side of the border. Vorderburg-I7 }\end{array}$ \\
\hline
\end{tabular}

perceive themselves as stewards of their village. Collective action, then, seemed to them to be a natural response, and the initiators realized that they had to assemble a core team around them to help them lead the process. For doing this, they strategically approached high-status community members who held leading positions in the village (e.g., chairmen of local associations) and thus could function as multipliers, and villagers who could bring in the required expertise, from conceptualization and financial budgeting to construction planning and implementation. We were surprised at how easy it was for the initiators to convince others to join the core teams-even though people knew that joining these teams would entail a very heavy load of unpaid labor and a great level of responsibility. Similarly, astonishing was the fact that the CBE initiators in Altenau managed to convince eight villagers to invest $€ 50,000$ each without expecting any returns on their investments. We then dug deeper into the backgrounds of the core team members and major investors in both cases and found that, with one exception, they shared an exceptionally high level of identification with their village. The data show that the initiators had convinced the others to get on board by appealing to their identity as villagers and by stressing the importance of their participation for the success of the entire CBE. Conversely, the evidence shows how difficult it was to convince the sole core team member without a high level of village identification to join the core team. In Altenau, the initial core team approached a good friend of theirs, who could bring their CBE necessary business expertise, but who had only moved to the village a few years prior. Interestingly, he was the only one who did not believe in the viability of the idea and initially refused to support it.
After the core team had developed a first detailed version of a business plan for the CBE, they approached the entire village to mobilize supporters for their collective endeavors. Our analysis of the video footage from Altenau's initial information event, at which the core team informed all villagers about their plans, enabled us to see how the core team consciously used identification when mobilizing the villagers. Before presenting their ideas for a $\mathrm{CBE}$, the core teams showed old photographs from the pub and social life in the village to elicit memories and so trigger a sense of identification (Figure 3).

Our findings show that a strong identification with one's village triggers a sense of collective agency. People with a strong identification with their village tend to have higher belief in the capability of the group and, therefore, a higher willingness to

\section{FIGURE 3 \\ Example of Harnessing Locals' Identification with Their Village: The First Information Event in Altenau}

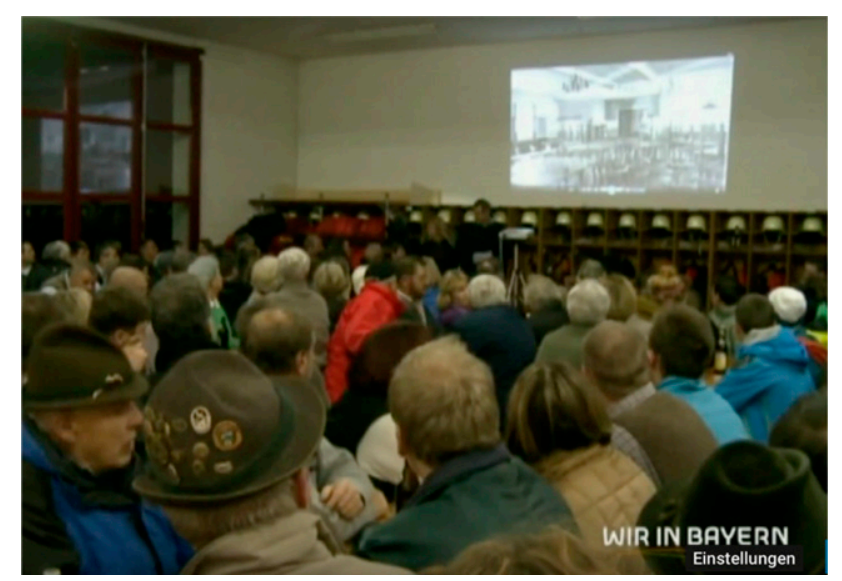


participate in collective action-even before knowing the details of that collective action. On the other hand, when community identification is low, individuals tend to hesitate to get involved. Overall, we found that a high level of identification with the village constitutes the nourishing ground for successful CBE creation. However, it does not suffice to explain the three breakdowns: 1) How can we explain why it took 12 years in Altenau to initiate CBE creation, whereas the community in Vorderburg immediately resorted to creating a CBE? 2) How can we explain that a lack, or withdrawal, of external support fueled CBE creation? 3) How can we explain why both cases managed to sustain, and even increase, commitment over such long periods of time? We dug deeper into our data and identified four different mechanisms that enhanced the locals' perceptions of the role of their identification with the village as a driver of entrepreneurial action.

Perception of an identity threat. A central finding emerged from examining the most striking difference between our two cases-the difference in time between the emergence of the problem and the inception of CBE creation. How can this difference be explained? And why did Altenau suddenly come up with the idea to solve their problem by means of CBE creation 12 years later, despite the fact that this had never been discussed as an option before? Our first assumption that Altenau had lower needs or a lower level of dissatisfaction was dispelled by our data. During a government development project in Altenau in 2008, officials asked villagers what problem in their community they thought should be addressed first. The vast majority of the villagers pointed to the lack of the local pub and village hall as the most pressing issue. However, even with governmental support, the villagers did not find any solution until 2012, when the owners of the building decided to sell it. Soon after, several prospective buyers-external investors-voiced an interest in tearing down the building and replacing it with a large new apartment block or hospice. We found evidence of a similar situation in Vorderburg, where an external construction company had voiced interest in demolishing the old building to make room for a new apartment block. These developments would have changed the structure of the villages by bringing in outsiders in high numbers and changing the old-established structure of the village center, and thus constituted threats to the villages as locals knew them. The villagers' fears are reflected in the following quotes:

And there were rumors about various potential buyers, who... For sure, they wouldn't have misused it... But... For example, a hospice association... Of course, that's an important topic, we all need to die one day, but in the middle of our village, directly next to the school? (...) Altenau-I5

We agreed that we had to decide what to do [...] If that would have been sold, if maybe a multifamily apartment block had been built there, that would have been a catastrophe for the village!

It was despair, you know, it really was despair. We were desperate. If this had happened... Do you understand that? Vorderburg-I2

Our data show that, in both cases, a sense of collective agency arose suddenly after the buildings' owners announced their intentions to sell their property to external actors who intended to repurpose them. Although a common problem (i.e., the lack of the pub as a meeting place and headquarters for local associations) had aroused high levels of dissatisfaction in Altenau over the years, the community required a triggering event to prompt the creation of a CBE. Thus, although a certain level of identification with a village is necessary for collective agency, a triggering event in the form of an explicit and acute threat to the village identity may be necessary to actually instigate CBE creation. This explanation is corroborated by how initiators strategically played on this fear to further mobilize core team members and supporters-e.g., by arguing that everyone's action mattered and was decisive for "safeguarding" the community as they knew it (Altenau-I3), or by "coming up with dramatic names for [the] meetings" (Vorderburg-I1). Overall, a perceived identity threat wound up being pivotal for the inception of CBE creation.

Comparison with similar groups. A community's comparison of their context to other rural communities with similar sociodemographic structures and problems emerged from our data as another facilitating mechanism. Early in the CBE creation process, the core team in Altenau organized an "espionage tour" to visit other successful CBEs, "to check out what others had been able to achieve" (Altenau-VF2). They also had connections with other rural communities in the area, which were facing similar problems, had convinced the municipalities to subsidize the local pub, but which were still facing significant challenges relating to economic viability. Their observations triggered a determination to respond to their problem with purely citizen-based collective action, showing "them" that "they" could do it by themselves—and be more successful while doing so. The following quote shows how the comparison with other villages motivated the core team in Altenau: 
I mean, if you look around, in any of the villages where the municipalities have agreed to take over the pub... They're all struggling, they're all facing serious problems. We definitely didn't want that. Altenau-I3

The core team in Vorderburg also invited other locals to visit other villages to inspire them, which had a strong motivational effect on the group, as reflected in this quote:

And then we said: "Well, okay, then let's drive there!" And then ten people went there with a small bus and they showed us their business and this was when it started. From then on, we knew that we wanted to do it. Vorderburg-I3

These visits triggered villagers' desire to prove that their community was at least as good, if not better, than other comparable villages, increasing their sense of collective agency and willingness to invest financial, natural, and human resources.

Perception of being challenged. A feeling of being challenged and let down by others emerged from our data as a third facilitating mechanism. Although it was always clear for the core teams that ownership should remain within their communities, and thus that the greatest part of their resources should be generated from the villagers, the core teams also explored external funding options. However, both communities encountered massive challenges when applying for external funding. In both cases, a large part of the scheduled external funds was cancelled during the CBE creation process because of unachievable requirements or changes in regulations. These difficulties, strikingly, did not constrain the communities in their endeavors, but instead seemed to enhance their determination to solve their problems as a strong, local collective. When the core team in Vorderburg decided to pause their project after the withdrawal of a substantial part of the subsidies, a large group of villagers showed up at the construction site to signal their decision to move forward with the project regardless, thereby motivating the core team to initiate their CBE without subsidies. One of the initiators in Vorderburg told us:

There were so many people who all said: "We want to start! When can we start?," and [Steffen] called me and said: "I can't hold them back, they want to get going now!” Vorderburg-I1.

The locals brainstormed possible alternatives for the lost subsidies. One individual came up with the idea of asking villagers who owned woodlands to donate wood. The community collected more than 200 cubic meters of wood, which was partially used for construction and partially sold to finance the
CBE. Overall, the lack of institutional support during the process enhanced the CBE supporters' motivation instead of diminishing it. In a similar vein, our data show that expressions of skepticism or a lack of belief by outsiders in the capability of the community's ability to achieve their goals did not fluster the supporters but instead stoked their ambition to prove skeptics wrong. As one supporter put it:

Let them talk... We will show them what we can achieve. Let's see if they are still critical when they see it in the end... Altenau-FN2

Perception of acknowledgement. Finally, in our interviews, we found that those involved in CBE creation frequently spoke about external actors' positive reactions to their projects and showed pride in these moments of recognition. Early in the CBE creation process in Altenau, BR, the main Bavarian TV channel expressed an interest in following the process. A broadcast team joined the CBE supporters at the construction site every second week and broadcasted an episode every week. The resultant TV micro series became the channel's most successful show at that time. Our interviewees from Altenau frequently remarked that they were quite proud that their village had become so famous, and this pride motivated them to work hard to show the whole country what they could achieve as a village. One of Altenau's core team members noted that people from the production team often complained that everything went smoothly during the construction process, so they could not capture any fights or crises. He also told us that this motivated those involved to avoid fighting even more to maintain the positive national image of their village. In addition, Altenau won a prestigious award even before they finished their construction process. The award ceremony was the first official event in the new pub; several interviewees mentioned this as a highly motivating development. One supporter told us:

Somehow, we won the national award from the Agency for Rural Development. And we were still in the middle of construction when they called and invited us to the ceremony. But nobody had time to go. But then the minister said, "Well, then I'm coming to you!" and then we had the ceremony in our own new village hall! And, that was like the icing on the cake for us! Altenau-I2.

We found evidence of similar mechanisms at work in Vorderburg. Most of the villagers we interviewed there spoke proudly about newspaper articles or television and radio reports featuring the creation of their CBE. In sum, this shows that external acknowledgement of achievements functioned 
as a powerful facilitating mechanism during CBE implementation.

Overall, a pronounced incumbent village identity combined with the locals' identification with their village appeared as a first enabler for successful CBE creation. However, although we found them to be the key explanations for collective agency and willingness to invest private resources, they do not fully account for the high level of lasting commitment we observed in our cases. Our analysis revealed another important enabler in the form of an emergent collective identity as an enterprising community and the associated supporters' identification with that enterprising community. In the next section, we offer evidence for this enabler and show how it enhances and sustains commitment.

\section{Enabler II: Emergent Enterprising Community Identity and Supporters' Identification with the Enterprising Community}

A key contribution of our study is the emergence of an enterprising community identity and supporters' identification with the enterprising community. After the development of an initial business plan, the core team invited the villagers to a community meeting in the collectively renovated fire brigade's houses and presented their ideas for the future of the village pub in the form of a CBE. They asked the villagers to support their business idea, get engaged, provide funding, and buy shares. This meeting and the subsequent engagement of the large majority of the villagers mark the outset of the formation of the enterprising community identity. During the construction process, the enterprising community identity developed further through continuous interaction, resulting in a distinct collective identity defined by a shared vision, new traditions, symbols, and rituals, anchored in the evolving enterprise.

Indeed, when comparing quotes from early in the CBE creation process with those from later, we observed that the meaning our respondents attached to the word "we" was changing over time. Although "we" was used to talk about "us as members of this village" early on, it later clearly referred to "us as active supporters of the CBE." Although the boundaries of the groups of villagers (i.e., people who have their roots in the village) are mostly impermeable and static (as reflected in Table 2), membership in the enterprising community was not determined by an individual's origins or history in the village, but by active support of the CBE creation. For example, people who had moved to the village many years prior had never been accepted as equal members of the group of villagers. Conversely, the nascent CBE attracted people from neighboring villages and tourists who had heard about the project and felt the desire to join in on it. When we asked "real" villagers about these neighboring villagers and tourist supporters, they seemed to accept them on equal terms with other "true" villagers as part of the enterprising community. We observed this dynamic firsthand: when the first author initially visited Vorderburg, the villagers welcomed her in a friendly, yet detached, manner. The villagers found it hard to understand why "someone from a university" would come to study them and their project. After she had stayed with them, helped on the construction site, and participated in CBE-related celebrations, however, she was no longer seen as a researcher, but as an equal member of the enterprising community.

Our data contain extensive, vivid descriptions of events and practices that made CBE creation work enjoyable. Interviewees repeatedly stressed how much fun they had had working together and how the experience of collectivity had become a major reason for their continuous commitment. Although the overall goal of preserving their village's identity still functioned as a motivational factor, people's desire to become a part of this newly emerging group-which seemed to be associated with much fun and be able to achieve so much collectivelystarted to prevail as a motivating factor. The effect of the emergent collective identity is reflected in the following quotes:

Amazing, brilliant... Once you had experience it-you only had to experience it once, and then there was no way back. Actually, we all wish we had another project. Seriously, really cool! Vorderburg-I5.

And then we always had so much fun! Really, sometimes people just came because they wanted to experience the atmosphere. I'm not kidding, it was really amazing. Altenau-I2.

Moreover, the emergence of the new, inclusive enterprising community made participation in the project attractive to people outside the village. In both villages, a great number of nonvillagers joined the projects during the implementation stage and actively supported CBE creation whenever possible. One man, who used to visit Vorderburg once a month, told us:

And then I saw them build this community house and I said: I want to join![...] And it's always fun. I'm grateful for being allowed to experience that. Vorderburg-I4

In sum, the data show how the emergence of a new collective identity of an enterprising community served as a powerful mechanism for sustaining the 
commitment of those who had already supported the project for other reasons and also encouraged new, external supporters to join in at later stages. The foundation for the new group with its distinct collective identity was laid when a large group of locals agreed to commit to the project by investing their resources. Although this new group automatically grew together and further shaped its identity through interaction and collective endeavors toward a common goal, our data reveal two mechanisms through which CBE initiators can explicitly reinforce collective identity emergence.

Creation and use of artifacts. Naturally, some cultural elements from the incumbent village identities were imprinted on the emergent collective identities of the enterprising communities. However, despite some overlap, new traditions and symbols emerged that were specific to the emergent enterprising community identity. Both communities, Altenau and Vorderburg, developed logos for their project and used these logos whenever possible-for instance, as flags on snacks provided for workers on the construction site, or during local festivities (Figure 4). Villagers also printed these logos on T-shirts that all the supporters wore with pride, not only on the construction site but also in their everyday lives, to signal their membership in their CBE (Figure 5).

In Vorderburg, one villager, a famous local folk musician, composed a song for the CBE and set up a recording studio on the construction site one weekend (Figure 6). She invited everyone to sing the chorus together and mixed an official song for the CBE. The CBE initiators played the song every week on the construction site and published it online. All interviewees asked us whether we had heard their

FIGURE 4

Example of the Use of Symbols: The Project Logo at a Concert by a Local Band in Vorderburg

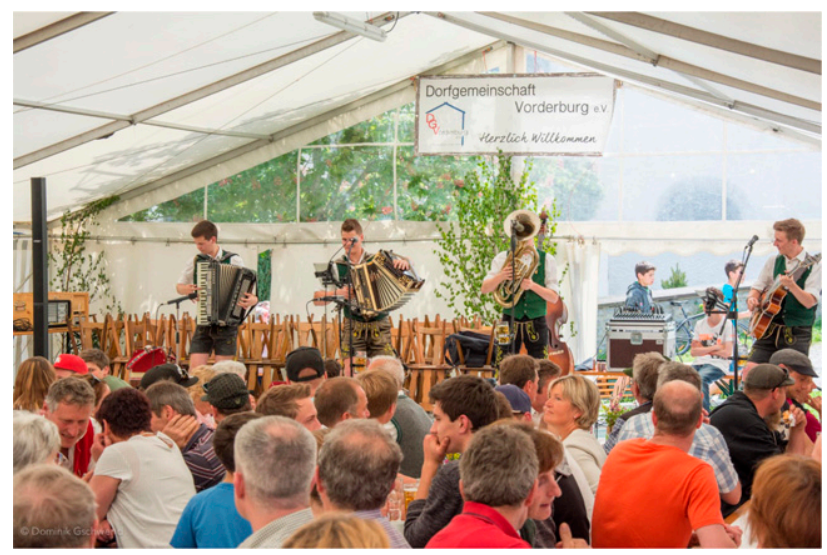

FIGURE 5

Example of the Creation and Use of Artifacts: Youth Wearing T-shirts with the Logo and the Slogan in Vorderburg

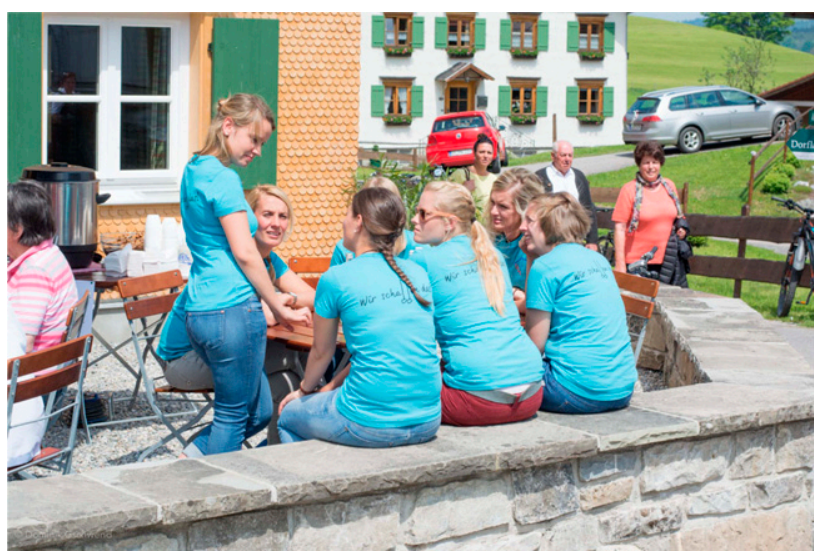

song. One of the core team members even started crying when telling us about it:

Of course, I also went there. You want to be part of something like that. And in the end, she played our song and I just stood there... That was... I cried and I had goose bumps like mountains. It's so touching to hear that and to know that you're part of it. [.. .] I still start crying just by thinking about it. It's really... You're part of that and then you hear that and start thinking, "My goodness, what have we done? What have we started here? That's incredible!" Vorderburg-1

FIGURE 6

Example of the Creation and Use of Artifacts: The Recording of the Village Song on the Construction Side in Vorderburg

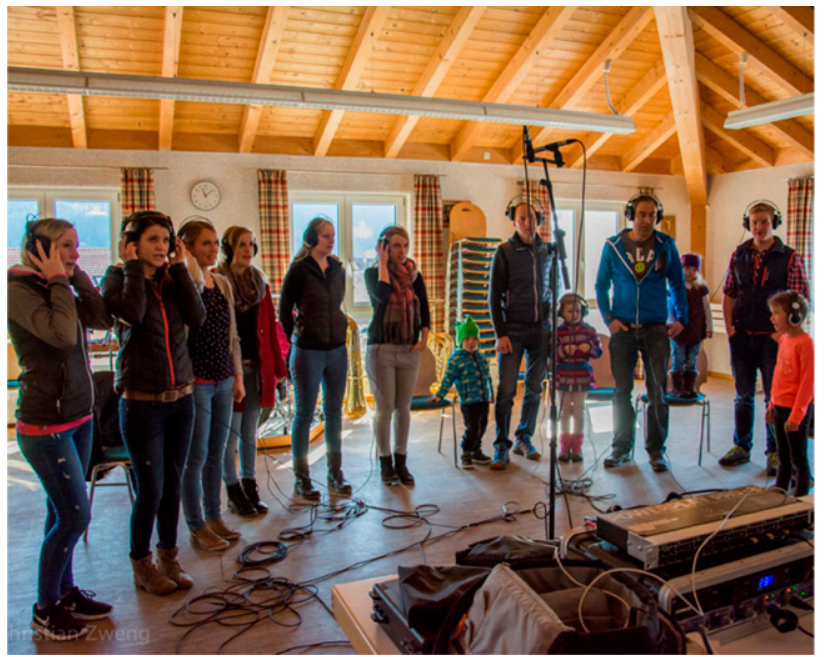


FIGURE 7

Example of the Creation and Use of Artifacts: Group Photo in Front of the Newly Built Pub in Vorderburg

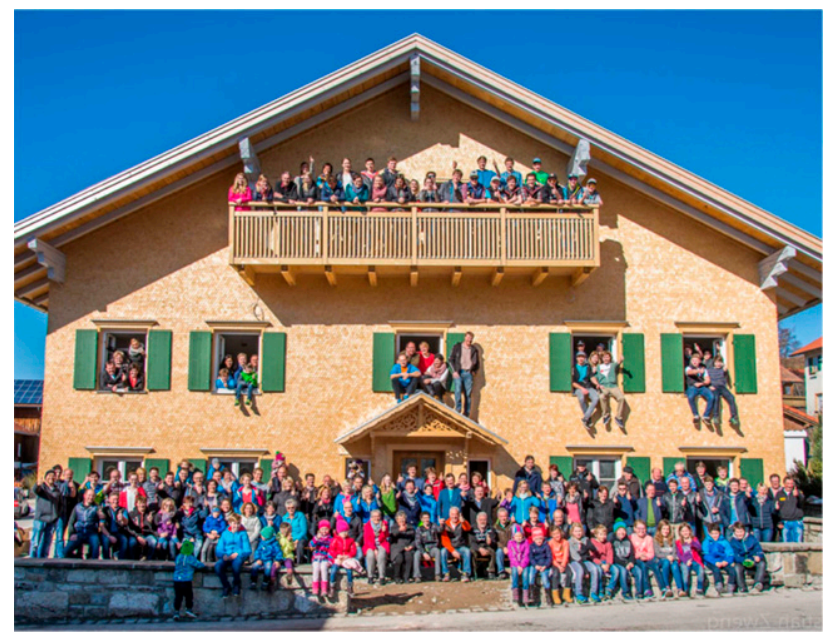

Furthermore, the community in Vorderburg regularly took pictures of their entire team of supporters in front of the pub to document their progress and the human scale of their support (Figure 7). Being in these pictures soon became a badge of honor.

Implementation of rituals and celebrations of achievements. Various rituals established throughout the CBE creation process emerged as a recurring theme in our data. Over the 16 months of implementation in Altenau and the 19 months in Vorderburg, most workdays on the construction sites followed the same ritual. In Vorderburg, days on site started at eight in the morning with the hardest jobs. At 10, the workers had their first short coffee break on-site

FIGURE 8 Example of a Weekly Ritual: Lunch on the
Construction Site in Vorderburg

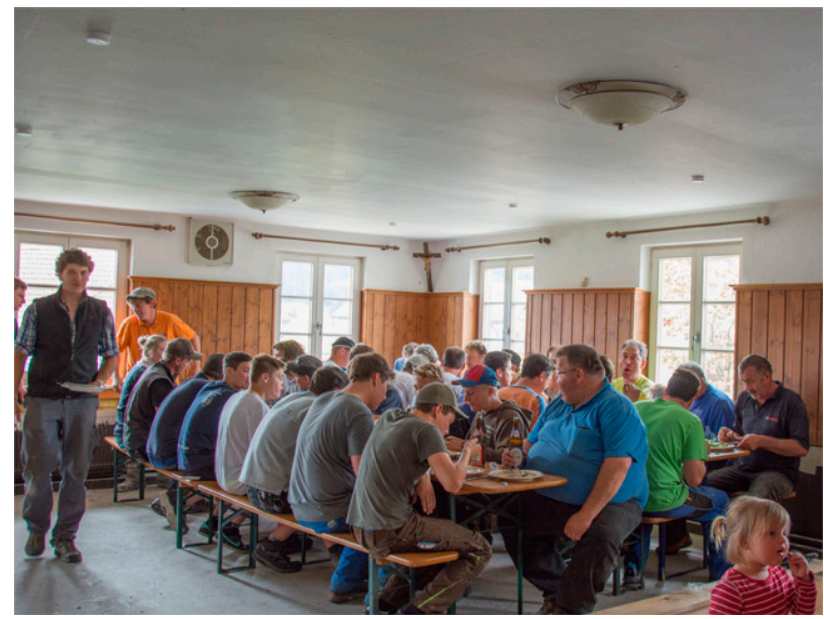

before they had a rich, warm lunch at 12, provided by a group of women from the village, or a local business (Figure 8). At three, they shared coffee, homemade cake, and a beer-a moment that soon became supporters' favorite ritual. From three in the afternoon on, workers switched over to easier jobs, such as cleaning. The workday eventually elided into a collective event, during which supporters ate and drank, viewed pictures from the day, showed each other what they had achieved, talked about the plans for the upcoming weeks, and mused about the eventual opening of the pub and life in the village afterward. The first author spent several days with the community on the construction site and participated in these events, which often lasted until late at night.

We found similar rituals in our data from Altenau, as well as statements about how crucial they were for group cohesion and commitment. For example, every time the group finished work on one room of their new pub, they moved tables there to celebrate their success. Over the weeks, senior citizens started organizing themselves in groups to paint, air out, or clean the site. These groups soon became popular socializing loci for the villagers.

At the end of the construction process, both Altenau and Vorderburg hosted large opening ceremonies that lasted several days (Figure 9). Although parts of the ceremonies were opened to the public, and attracted hundreds of people from the broader area, other parts were only for the community of supporters, whose efforts were acknowledged and celebrated there. In sum, our data show that, by establishing rituals, especially celebrations of collective achievements, the CBE initiators reinforced the emergence of a collective identity associated

FIGURE 9

Example of a Celebration of Collective Success: The Opening Ceremony for the CBE in Vorderburg

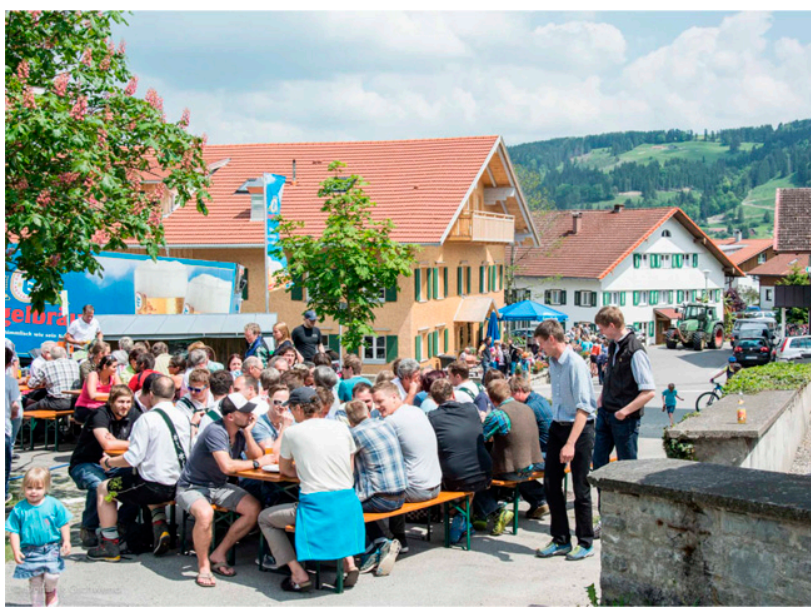


with the enterprising community, thereby fostering lasting commitment to the CBE.

\section{DISCUSSION}

We have presented two stories of rural communities that, enabled by the locals' identification with their village and an emergent collective identity as an enterprising community, successfully created CBEs, which not only solved a specific local problem but also yielded additional social and economic benefits for the sustainability of their communities. These are success stories of sustainable development solutions originating at the local level in the form of CBEs. They highlight the important role that rural communities can play in achieving the SDGs and extend understandings of how untapped community capacity can be harnessed to address problems in rural communities.

\section{Contributions to Understanding of CBE Creation}

Our main goal in this study was to explore the factors that enable successful CBE creation in rural communities. Despite growing acknowledgement of the potential of CBEs for addressing societal problems, we still know very little about how and why these enterprises emerge (Daskalaki et al., 2015) and why some communities seem to be more amenable to forming them than others (Peredo \& Chrisman, 2006). We make three distinct contributions to this literature.

Key prerequisites. Our first contribution is to identify three key prerequisites imperative for successful CBE creation. Various researchers have raised the question of why most rural communities facing problems remain inactive, whereas others decide to tackle these problems on their own, through collective action (e.g., Daskalaki et al., 2015; Peredo \& Chrisman, 2006; Rao \& Greve, 2018). Our data provide empirical evidence of the importance of locals' shared sense of collective agency, which influences the future they envision for their village and the type of action they choose to engage in (Bandura, 2000), thereby laying the groundwork for CBE creation. The actual implementation of a CBE requires multiple forms of capital and resources invested by different community actors at different points in time (Haugh, 2007). Hence, a CBE can only come into existence if enough people show a willingness to invest their private resources toward this common goal. Finally, our data show that CBE creation is a lengthy and strenuous process that requires lasting commitment from its supporters until-and beyond-the CBE opening (Haugh, 2007; Valchovska \& Watts, 2016). CBEs can only be established successfully if all three of these prerequisites come together in a community. Identifying these prerequisites offers a greater understanding of the CBE creation process and its enabling factors, and opens avenues for future research into each prerequisite, its antecedents, and distinct effects. In particular, future research could further investigate the effect of individual-level factors (e.g., personal motivation and background of the core team members) and community-level factors (e.g., a history of collective action or other preexisting social and cultural resources available to the community) on CBE creation.

The role of an incumbent village identity and locals' identification with the village. Our second contribution is to elaborate on the role of the incumbent village identity and the locals' identification with their village as the first enabler of CBE creation. With extant literature suggesting that factors like local culture and a history of collective action are antecedents of CBE creation (Peredo \& Chrisman, 2006; Vestrum, 2014), the relevance of locals' identification with their village might not come as a complete surprise. However, we extend understanding on this topic in two important ways.

First, we showed how the initiators of CBE projects can strategically harness identification to appeal to potential supporters' identification with their village. The question of why some people are willing to bear personal costs to solve common problems is not new; the issue of free riding is discussed extensively in collective action literature (Olson, 1965; Ostrom, 1999; Pearce, 1980). Social identification serves as a framework for interpreting information (Tajfel \& Turner, 1979) and can generate optimism and perseverance (Ashforth et al., 2008). According to Gamson (1992), people will act to solve a common problem if they feel that no one else will tackle it. Our evidence shows that initiators can harness these effects for stakeholder mobilization by eliciting identification and emphasizing the decisiveness of locals' participation for the success of the entire CBE, thereby "safeguarding" the incumbent village identity. Previous research has pointed to the importance of other activities, such as writing a business plan, for stakeholder mobilization (Haugh, 2007). Our data show that, although a comprehensive business plan was not necessary to convince people with a strong identification with the village, it helped win over individuals with lower levels of identification. By proposing that identification is a key enabling mechanism, we do not suggest that conventional business development practices do not matter for CBE creation. They are-likely-as important to ensure the viability of a CBE as they are in any other kind of business and can be used as complementary 
means to convince potential supporters with a lower level of identification. In addition, future research ought to explore the effects of different funding models, decision-making processes, and organizational and governance structures-all factors that could be contingent on the level of identification with the village and the enterprise-on the inception, and the short- and long-term success of CBEs.

Second, we showed that, although identification with a group has a strong motivational effect, as suggested in previous literature (Ashforth et al., 2008; Stryker et al., 2000), and thus can serve as the "birthing condition" for a change-oriented group (Gutierrez, Howard-Grenville, \& Scully, 2010: 695), it does not suffice to enable successful CBE creation. To wit, CBEs will not simply emerge in any village that faces a problem, and with which locals strongly identify. Our data show that identification functions as the propellant, but requires certain catalysts to initiate and/or facilitate action. Individuals identify with multiple groups at the same time, and these identities are organized hierarchically (Hogg et al., 1995). An identity only has behavioral effects and forms the basis for cooperation toward a common goal if it is salient (Hogg et al., 1995). The four facilitating mechanisms we identified all enhance the salience of incumbent village identity in this particular situation.

The most important facilitating mechanism we identified was the perception of an identity threat. Identity threats-events that challenge group members' beliefs about central and distinctive attributes of a group (Bartel \& Wiesenfeld, 2013; Ravasi \& Schultz, 2006)—tighten in-group boundaries, enhance solidarity, and elicit strong emotional and behavioral responses (Gutierrez et al., 2010; Marquis \& Lounsbury, 2007). In our study, a perception of an in-group threat proved decisive for CBE inception and provided an explanation for the question of why 12 years passed between the emergence of a problem and CBE inception in one case. Although extant research has equated the identification of a problem with the initiation of CBE creation (Haugh, 2007), our study shows that problem identification and CBE inception are two distinct events. By adding this missing puzzle piece to our understanding of CBE creation, our study makes an important contribution to extant research and suggests a need for future research on the types of identity threats that may trigger CBE inception in other contexts.

The second mechanism we identified was the comparison with similar groups. Our evidence shows that both communities we observed compared themselves with other villages that resembled their own in size, sociodemographic structures, and culture, and had been either particularly successful or unsuccessful in solving similar problems. Intergroup comparison is a central process in social identity theory (Abrams \& Hogg, 2006) and has been found to facilitate collective action (Brewer \& Silver, 2000). By showing how CBEs can inspire and impel each other as a basis for intergroup comparison, we contribute to Peredo and Chrisman's (2006) call for investigations into how CBEs can support each other, and whether and how established CBEs can foster the creation of new ones in other communities.

Third, the perception of being challenged emerged as a facilitating mechanism. Although we at first could not explain why skepticism and a lack, or withdrawal, of support seemed to have a motivational effect on local communities, the identity lens provided an explanation: by withdrawing subsidies and challenging the community, governmental institutions acted as out-groups (Ross, 2007). Given that awareness of an out-group is related to awareness of the in-group (Ashforth \& Mael, 1989), and that being challenged encourages individuals to draw sharper boundaries around their in-group, out-group emergence enhances identity salience and facilitates action (van Knippenberg, 1984). Although the idea of collective action in response to a common foe, or contestation, is not new to social movements and collective action literatures (Rao, Yue, \& Ingram, 2011; Ross, 2007; White \& Fraser, 2000), it is new to the study of entrepreneurship. Future research is required to explore how and under which conditions a lack of governmental support facilitates or impedes successful CBE creation.

Finally, we found that people's perception of acknowledgement facilitated CBE creation. Indeed, as our findings suggest, external interest in and acknowledgement of a CBE's efforts, such as media coverage or awards, were highly motivational. Indeed, people who strongly identified with a group perceive the success of the collective as their personal success (Tolman, 1943), which in turn stokes their desire to achieve even more (Ashforth \& Mael, 1989). Although this might not be the most surprising finding, it is of high practical relevance because it stresses the importance of public awards as stages for CBEs to present themselves to both similar communities and a broader audience.

The role of an emergent enterprising community identity and supporters' identification with the enterprising community. Our third, and possibly most significant, contribution was to illuminate the importance of an emergent collective identity of an enterprising community. Although locals' identification with their village, facilitated by the four mechanisms described earlier, spurs the first two prerequisites of successful CBE creation, a novel collective identity forming around and within the enterprising 
community emerged as the best explanation for the high level of lasting commitment. Existing CBE research has tended to equate a village with the enterprising community (Peredo \& Chrisman, 2006). Our empirical evidence, however, clearly points to the emergence of a new group with distinct, more inclusive membership criteria based on active participation in a CBE's creation, not an individual's origins or history in a village. Social movements and collective action literatures often discuss the problem of decreasing participation over time despite initially successful mobilization efforts (Klandermans \& Oegema, 1987; Stryker, 2000). Our study adds to the CBE literature by revealing that an emergent collective identity as an enterprising community is not only pivotal for the success of the endeavors, as it secures supporters' lasting commitments, but also as the enterprising community is also open to nonvillagers, thereby extending a CBE's pool of potential supporters. Although parts of the values and culture associated with the incumbent village identity certainly are imprinted on the emergent collective identity, the enterprising community also develops its own idiosyncratic collective identity. Future research ought to focus on this emergent identity and the-potentially reciprocal-relationship between it and the incumbent village identity.

Strategies for reinforcing collective identity emergence. New collective identities emerge as a result of repeated interaction between individuals within a certain group, and are shaped by shared goals (Gioia, Price, Hamilton, \& Thomas, 2010; Melucci, 1996). As such, their emergence coincides with the first interactions among the participating group members-in our cases, the first information events-and are then further developed and shaped over time. Besides, through interaction between leaders and all supporters, collective identities emerge through sense-giving by leaders (Pratt, 2000). Given their legitimacy as well-respected community members in great standing in their respective community, CBE initiators can exert direct influence on collective identity emergence (Howard-Grenville et al., 2013; Ravasi \& Schultz, 2006). Along these lines, we identify two explicit strategies they can employ to reinforce an emergent enterprising community identity. First, CBE initiators can create artifacts that codify core meanings associated with an emergent identity. As collective identities manifest through the symbols and artifacts by which they are publicly expressed (Gamson, 1992; Glynn, 2008), the development of symbols and artifacts and their use are an easy way for leaders to form and/or reinforce an emergent collective identity. Second, our data point to the importance of rituals and the celebrations of collective achievements. Through rituals and collective events, supporters grow increasingly attached to a new group and perceive its collective achievements as their own (Ashforth \& Mael, 1989; Stryker, 2000). By unraveling these specific tactics for reinforcing a motivating collective identity, we contribute to extant CBE research by showing how CBE initiators can gain, and sustain, community support, even over long periods of time (Lobo, Velez, \& Puerto, 2016; Selsky \& Smith, 1994; Valchovska \& Watts, 2016). There remains, however, ample room and need for further research on the role of leaders' and other actors' characteristics and behaviors on collective identity emergence.

\section{Theoretical Implications for Other Streams of Research}

The phenomenon of CBE creation combines elements of collective action and social movements with elements of entrepreneurship and organizing. As such, it is not surprising that our empirical exploration of successful CBE creation also holds implications for multiple literatures. Interestingly, few researchers have connected research on CBEs and prosocial organizing (e.g., Daskalaki et al., 2015); in addition, to the best of our knowledge, only one study to date has alluded to a link between CBE research and collective action literature (Montgomery, Dacin, \& Dacin, 2012). Future research is needed to further explore how, and to what extent, assumptions and findings from these different literature streams can inform our understanding of CBEs, and vice versa. In the following, we discuss some ways in which our study, and CBE research in general, can extend knowledge on the relationship between local communities and organizations, on identity processes in organizations, and on collective action and prosocial forms of organizing.

Various organizational researchers have acknowledged the reciprocal relationship between local communities and organizations (Freeman \& Audia, 2006; Glynn, 2008; Howard-Grenville et al., 2013; Marquis \& Battilana, 2009; Marquis et al., 2007; Marquis \& Lounsbury, 2007; Romanelli \& Khessina, 2005). By showing how a threat to a strong collective identity can lead to the emergence of new organizations and collective identities, this article has heeded calls for further explorations of how local communities can affect organizational emergence and behavior (Marquis et al., 2007; Marquis \& Lounsbury, 2007; Williams \& Shepherd, 2016). Although prior studies have shown how threats to local communities lead to the emergence of profit-driven noncollective ventures (e.g., Marquis \& Lounsbury, 2007), profitdriven collective ventures (e.g., Rao \& Greve, 2018), or prosocial noncollective ventures (e.g. Williams \& Shepherd, 2016), our study provides evidence 
for the emergence of prosocial collective ventures (i.e., CBEs), in face of an external threat, thereby distinguishing itself from prior work. By developing a social mission for the enterprise and engaging the broader community, the CBE initiators were able to gather the financial and human resources that were required for successful venture creation but were missing in the core team. This finding extends past evidence that the availability of experts within the sector of the new venture is important for the emergence of a new venture in the face of a threat (Marquis \& Lounsbury, 2007). Further studies may be able to better capture when and why a threat to a community can or will lead to profit-driven versus prosocial organizing efforts, and/or to individual versus collective action-and with what effect for the entrepreneurial process and its impact on the community.

Moreover, future research is needed to develop a better understanding of the effects of the emergent enterprising communities and their collective identities on the incumbent communities, their collective identities, and their abilities to react to external threats (cf. Marquis et al., 2007; Marquis \& Lounsbury, 2007; Rao \& Greve, 2018; Williams \& Shepherd, 2016). Rao and Greve (2018) have stressed the importance of civic capacity for community resilience. We argue that both the process of CBE creation and the resulting business directly contribute to community resilience. Values such as solidarity, collaboration, trust, and collective agency are innate elements of the emergent enterprising community identity and will most likely also have an imprinting effect on the original village's collective identity. As such, the creation of a CBE may not only solve an acute societal problem but also constitute an important step on a community's path "from vulnerability to resilience" (van der Vegt et al., 2015: 972).

In addition, it is worth recognizing that CBEs are not the only type of organization inextricably imprinted by the identities of the local communities in which they are embedded. For example, existing research has discussed the effects of local communities on organizations such as universities, hospitals, or governmental agencies, in which a community identity is an immanent component of the organization's identity (cf. Howard-Grenville et al., 2013). Such imprinting effects might also play an important, yet under-researched, role in locally embedded entrepreneurial ventures, and particularly in locally embedded social ventures (cf. Seelos, Mair, Battilana, \& Dacin, 2011). Future research thus ought to explore how imprinting mechanisms could be strategically harnessed to enhance new ventures' and organizations' economic and social performance (Nason, Bacq, \&
Gras, 2018). This is particularly relevant as an increasing number of social enterprises build on some form of local collective action (Corner \& Ho, 2010; Le Ber \& Branzei, 2010; Powell, Hamann, Blitzer, \& Baker, 2018).

Furthermore, although existing research has already acknowledged local communities as interesting settings for the study of identity processes (Glynn, 2008; Howard-Grenville et al., 2013), the vast majority of studies thus far have focused on singlelevel analysis, leaving many open questions about the cross-level unfolding of identity dynamics (Ashforth et al., 2011; Gioia et al., 2013). Identity and identification are concepts that "travel easily across levels of analysis" (Albert et al., 2000: 13). We suggest that CBEs may serve as auspicious contexts, allowing the combination of different theoretical perspectives for the study of identity dynamics across multiple levels. CBE creation involves individuals with distinct individual-level identities and memberships in existing groups, who form new groups and organizations with emergent collective identities. As such, the context surrounding their creation is well suited to the study of mutual effects of identities on multiple levels, as well as their cocreation. In addition, recent research has outlined how different individual-level identities may explain the creation of ventures that benefit known and unknown others (Fauchart \& Gruber, 2011; Gruber \& MacMillan, 2017). Taking our research further, researchers should explore how differences in individual-level identities affect collective and organizational identities, and vice versa.

CBEs bring together individuals with different backgrounds and experiences, and studying their core teams and broader enterprising communities might also yield important implications for the study of new venture teams (cf. Klotz, Hmieleski, Bradley, \& Busenitz, 2014). Moreover, the context of CBEs also offers multiple other opportunities for future research that could draw from and contribute to the general entrepreneurship literature. For instance, future research ought to explore other individual-level mechanisms that trigger and facilitate successful CBE emergence, such as emotional benefits incurred by participating individuals (Cardon, Foo, Shepherd, \& Wiklund, 2012; Cardon, Post, \& Forster, 2017), or the effects of core team members' motivations (McMullen \& Bergman, 2017; Renko, 2013) on short- and long-term participation. CBEs also offer a fruitful setting for exploring the process and outcomes of collective opportunity discovery, co-creation, and exploitation (Sarasvathy \& Ramesh, 2019; Shepherd, 2015; Shepherd \& Patzelt, 2017), or the growing stream of research on collective forms of funding entrepreneurial 
ventures (McKenny, Allison, Ketchen, Short, \& Ireland, 2017; Short, Ketchen, McKenny, Allison, \& Ireland, 2017).

Finally, future research will also have the opportunity to explore some of the limitations of this study by, e.g., examining the phases of CBE creation beyond the inception and early implementation stages, elements of CBEs' growth and long-term sustainability, and cases of failed CBE creation for comparison with the successful CBE creation cases presented in this article. Although our qualitative research design allowed us to gain a much-needed empirically grounded understanding of successful CBE creation, future research using quantitative methods will be necessary to test the generalizability of the mechanisms we have herein proposed across different contexts and in developing nations.

\section{Practical Implications and Policy Recommendations}

Because we found that identification with a village is key for successful CBE creation, practitioners should focus on conditions that enhance or diminish incumbent village identities and locals' identification with their village. The following questions remain to be addressed: How can incumbent village identities be sustained or enhanced? How can their diminishment be avoided? As our data show, strong associations and places where people can enact their collective identities maintain and foster incumbent village identities. Strengthening local culture and associations and preserving meeting hubs therefore seem to be good starting points for local governments to enhance collective identities in rural communities. Furthermore, the four facilitating mechanisms this study has identified suggest policy recommendations. Our data show how comparison with best practice cases can inspire and motivate communities to develop similar solutions. We thus call for the creation of networks of successful CBEs that can spread their stories in other rural communities. In addition, this study has shown how awards and public attention can propel collective action. Overall, policy programs that enhance the popularity of the CBE concept are key for leveraging the untapped potential of villages.

In addition, our study reveals that a lack of institutional support did not impede but rather facilitated the implementation of CBE plans in both cases observed. This finding requires further consideration. It would be overly naive-if not dangerous-to conclude that governments seeking to support the creation of future CBEs should focus on refusing to allocate, or withdrawing, funds from communities. In recent years, many support programs for rural development have been established on national and international levels. Although in some countries, such as the United Kingdom, these policies seem to have yielded successes (Bailey, 2012; Somerville \& McElwee, 2011), other studies have noted shortcomings in such policy programs (e.g., Kleinhans, 2017). Our empirical evidence from two villages in Germany has illustrated that the regulations underlying some large-scale policy programs can be impossible to comply with. Policy-makers should work to develop better congruity between institutional offerings and community needs and possibilities. Finally, we have shown that creating a collective enterprising community identity is crucial for sustained commitment. According to our knowledge, to date, governmental and private CBE consultancies mainly focus on the early stages of CBE creation, such as market analyses and fundraising. Governments and consultants should expand their programs and advise communities on how to build strong collective identities.

\section{CONCLUSION}

Rural communities' potential to address urgent SDGs have not been adequately harnessed to date (UNDP, 2018; UNDP Environment and Energy Group, 2010). A central question that has concerned practitioners and scholars alike is: Why are some local communities finding ways to act in the face of problems, whereas others seem to be unable to do so (cf. Rao \& Greve, 2018; van der Vegt et al., 2015)? By providing extensive empirical evidence from two rural communities that have successfully harnessed local resources to establish CBEs, our study contributes to this conversation by explicating the importance of an incumbent village identity and an emergent enterprising community identity, and by exploring several mechanisms that trigger and facilitate successful CBE creation. In doing so, our study illuminates multiple pathways for how underresearched CBEs can serve as a fruitful context for organization and entrepreneurship research. We hope this work will encourage scholars to conduct further research on this timely topic, inhabitants of rural communities in developed nations to initiate similar projects, and policy-makers to support communities in these endeavors.

\section{REFERENCES}

Abrams, D., \& Hogg, M. A. 2006. Social identifications: $\boldsymbol{A}$ social psychology of intergroup relations and group processes. London: Routledge.

Agar, M. H. 1986. Speaking of ethnography, vol. 2. London: Sage. 
Albert, S., Ashforth, B. E., \& Dutton, J. E. 2000. Organizational identity and identification: Charting new waters and building new bridges. Academy of Management Review, 25(1): 13-17.

Albert, S., \& Whetten, D. A. 1985. Organizational identity. In L. L. Cummings, \& B. M. Staw (Eds.), Research in organizational behaviour, vol. 7: 263-295. Greenwich, CT: JAI Press.

Alvesson, M., \& Kärreman, D. 2007. Constructing mystery: Empirical matters in theory development. Academy of Management Review, 32(4): 1265-1281.

Ashforth, B. E., Harrison, S. H., \& Corley, K. G. 2008. Identification in organizations: An examination of four fundamental questions. Journal of Management, 34(3): 325-374.

Ashforth, B. E., \& Mael, F. 1989. Social identity theory and the organization. Academy of Management Review, 14(1): 20-39.

Ashforth, B. E., Rogers, K. M., \& Corley, K. G. 2011. Identity in organizations: Exploring cross-level dynamics. Organization Science, 22(5): 1144-1156.

Bailey, N. 2012. The role, organisation and contribution of community enterprise to urban regeneration policy in the UK. Progress in Planning, 77(1): 1-35.

Bandura, A. 2000. Exercise of human agency through collective efficacy. Current Directions in Psychological Science, 9(3): 75-78.

Bartel, C. A., \& Wiesenfeld, B. M. 2013. The social negotiation of group prototype ambiguity in dynamic organizational contexts. Academy of Management Review, 38(4): 503-524.

Bayern SPD Landtagsfraktion. 2016. Jede vierte Bayerische kommune ohne lebensmittelmarkt. Retrieved from https://bayernspd-landtag.de/presse/pressemitteilungen/ ?id=319182. Accessed January 29, 2019.

Besser, T. L. 2009. Changes in small town social capital and civic engagement. Journal of Rural Studies, 25(2): 185-193.

Brewer, M. B., \& Silver, M. D. 2000. Group distinctiveness, social identification and collective mobilization. In S. Stryker, T. J. Owens, \& R. W. White (Eds.), Self, identity and social movements: 153-171. Minneapolis, MN: University of Minnesota Press.

Cabras, I., \& Mount, M. P. 2017. Assessing the impact of pubs on community cohesion and wellbeing in the English countryside: A longitudinal study. International Journal of Contemporary Hospitality Management, 29(1): 489-506.

Cabras, I., \& Reggiani, C. 2010. Village pubs as a social propellant in rural areas: An econometric study. Journal of Environmental Planning and Management, 53(7): 947-962.
Cardon, M. S., Foo, M. D., Shepherd, D., \& Wiklund, J. 2012. Exploring the heart: Entrepreneurial emotion is a hot topic. Entrepreneurship Theory and Practice, 36(1): 1-10.

Cardon, M. S., Post, C., \& Forster, W. R. 2017. Team entrepreneurial passion: Its emergence and influence in new venture teams. Academy of Management Review, 42(2): 283-305.

Cieslik, K. 2016. Moral economy meets social enterprise community-based green energy project in rural Burundi. World Development, 83: 12-26.

Corley, K. G., \& Gioia, D. A. 2004. Identity ambiguity and change in the wake of a corporate spin-off. Administrative Science Quarterly, 49(2): 173-208.

Corner, P. D., \& Ho, M. 2010. How opportunities develop n social entrepreneurship. Entrepreneurship Theory and Practice, 34(4): 635-659.

Dana, L. P., \& Light, I. 2011. Two forms of community entrepreneurship in Finland: Are there differences between Finnish and Sámi reindeer husbandry entrepreneurs? Entrepreneurship \& Regional Development, 23(5-6): 331-352.

Daskalaki, M., Hjorth, D., \& Mair, J. 2015. Are entrepreneurship, communities, and social transformation related? Journal of Management Inquiry, 24(4): 419-423.

Denzin, N., \& Lincoln, Y. 2000. Handbook of qualitative research. Thousand Oaks, CA: Sage.

Dubb, S. 2016. Community wealth building forms: What they are and how to use them at the local level. Academy of Management Perspectives, 30(2): 141-152.

European Commission. 2014. Community-led local development. Available at http://ec.europa.eu/regional_ policy/sources/docgener/informat/2014/community en.pdf. Accessed January 29, 2019.

Fauchart, E., \& Gruber, M. 2011. Darwinians, communitarians, and missionaries: The role of founder identity in entrepreneurship. Academy of Management Journal, 54(5): 935-957.

Freeman, J. H., \& Audia, P. G. 2006. Community ecology and the sociology of organizations. Annual Review of Sociology, 32: 145-169.

Gamson, W. A. 1992. Talking politics. Cambridge, UK: Cambridge University Press.

Gioia, D. A., Patvardhan, S. D., Hamilton, A. L., \& Corley, K. G. 2013. Organizational identity formation and change. Academy of Management Annals, 7(1): 123-193.

Gioia, D. A., Price, K. N., Hamilton, A. L., \& Thomas, J. B. 2010. Forging an identity: An insider-outsider study of processes involved in the formation of organizational 
identity. Administrative Science Quarterly, 55(1): $1-46$.

Glynn, M. A. 2008. Configuring the field of play: How hosting the Olympic Games impacts civic community. Journal of Management Studies, 45(6): 1117-1146.

Gruber, M., \& MacMillan, I. C. 2017. Entrepreneurial behavior: A reconceptualization and extension based on identity theory. Strategic Entrepreneurship Journal, 11(3): 271-286.

Gutierrez, B., Howard-Grenville, J., \& Scully, M. A. 2010. The faithful rise up: Split identification and an unlikely change effort. Academy of Management Journal, 53(4): 673-699.

Hammersley, M., \& Atkinson, P. 2007. Ethnography: Principles in Practice. London: Routledge.

Handy, F., Cnaan, R. A., Bhat, G., \& Meijs, L. C. 2011. Jasmine growers of coastal Karnataka: Grassroots sustainable community-based enterprise in India. Entrepreneurship \& Regional Development, 23(5-6): 405-417.

Hanson, N. R. 1958. Patterns of discovery: An inquiry into the conceptual foundations of science. Cambridge, UK: Cambridge University Press.

Haugh, H. 2007. Community-led social venture creation. Entrepreneurship Theory and Practice, 31(2): 161-182.

Hertel, C. J., \& Belz, F. M. 2017. Community entrepreneurship: A systematic review, conceptual clarifications and future directions. Academy of Management Proceedings, 1: 11199.

Hogg, M. A., \& Abrams, D. 1988. Social identifications. London: Routledge.

Hogg, M. A., Terry, D. J., \& White, K. M. 1995. A tale of two theories: A critical comparison of identity theory with social identity theory. Social Psychology Quarterly, 58(4): 255-269.

Hopfinger, H., Kohnle, F., \& Wätzold, T. 2013. Genuss mit heschichte? Die wirtshauskultur in Bayern im wandel. Retrieved from https:/www.dehoga-bayern.de/fileadmin/ user_upload/02_Aktuelles/07_Daten_und_Fakten/ 03_Umfragen/WirtshauskulturImWandel_2013_1912.pdf. Accessed January 29, 2019.

Howard-Grenville, J., Metzger, M. L., \& Meyer, A. D. 2013. Rekindling the flame: Processes of identity resurrection. Academy of Management Journal, 56(1): 113-136.

IFAD. 2018. Transforming rural lives-Building a prosperous and sustainable future for all. Retrieved from https://www.ifad.org/en/web/knowledge/publication/ asset/40774229. Accessed January 29, 2019.

Johnstone, H., \& Lionais, D. 2004. Depleted communities and community business entrepreneurship: Revaluing space through place. Entrepreneurship $\&$ Regional Development, 16(3): 217-233.
Klandermans, B., \& Oegema, D. 1987. Potentials, networks, motivations, and barriers: Steps towards participation in social movements. American Sociological Review, 52(4): 519-531.

Kleinhans, R. 2017. False promises of co-production in neighbourhood regeneration: The case of Dutch community enterprises. Public Management Review, 19(10): 1500-1518.

Klotz, A. C., Hmieleski, K. M., Bradley, B. H., \& Busenitz, L. W. 2014. New venture teams: A review of the literature and roadmap for future research. Journal of Management, 40(1): 226-255.

Kühne, S., Seibold, M., \& Zierer, M. 2016. Nahversorgung in gefahr. BR data. Retrieved from http://web.br.de/ interaktiv/ladensterben. Accessed January 29, 2019.

Langley, A. 1999. Strategies for theorizing from process data. Academy of Management Review, 24(4): 691-710.

Le Ber, M., \& Branzei, O. 2010. Towards a critical theory of value creation in cross-sector partnerships. Organization, 17(5): 599-629.

Lincoln, G. 2006. Diversification in rural pubs: A strategy for survival and community value? International Journal of Entrepreneurship and Small Business, 3(3-4): 329-347.

Lobo, I., Velez, M., \& Puerto, S. 2016. Leadership, entrepreneurship and collective action: A case study from the Colombian Pacific region. International Journal of the Commons, 10(4): 982-1012.

Lumpkin, G. T., Bacq, S., \& Pidduck, R. J. 2018. Where change happens: Community-level phenomena in social entrepreneurship research. Journal of Small Business Management, 56(1): 24-50.

Mantere, S., \& Ketokivi, M. 2013. Reasoning in organization science. Academy of Management Review, 38(1): 70-89.

Marquis, C., \& Battilana, J. 2009. Acting globally but thinking locally? The enduring influence of local communities on organizations. Research in Organizational Behavior, 29: 283-302.

Marquis, C., Glynn, M. A., \& Davis, G. F. 2007. Community isomorphism and corporate social action. Academy of Management Review, 32(3): 925-945.

Marquis, C., \& Lounsbury, M. 2007. Vive la résistance: Competing logics and the consolidation of US community banking. Academy of Management Journal, 50(4): 799-820.

Maye, D., Ilbery, B., \& Kneafsey, M. 2005. Changing places: Investigating the cultural terrain of village pubs in South Northamptonshire. Social and Cultural Geography, 6(6): 831-847.

McKenny, A. F., Allison, T. H., Ketchen Jr, D. J., Short, J. C., \& Ireland, R. D. 2017. How should crowdfunding research evolve? A survey of the entrepreneurship 
theory and practice editorial board. Entrepreneurship Theory and Practice, 41(2): 291-304.

McMullen, J. S., \& Bergman Jr, B. J. 2017. Social entrepreneurship and the development paradox of prosocial motivation: A cautionary tale. Strategic Entrepreneurship Journal, 11(3): 243-270.

Melucci, A. 1996. Challenging codes: Collective action in the information age. Cambridge, MA: Cambridge University Press.

Miles, M. B., Huberman, A. M., \& Saldana, J. 2014. Qualitative data analysis: A sourcebook. Beverly Hills, CA: Sage.

Montgomery, A. W., Dacin, P. A., \& Dacin, M. T. 2012. Collective social entrepreneurship: Collaboratively shaping social good. Journal of Business Ethics, 111(3): 375-388.

Mount, M., \& Cabras, I. 2016. Community cohesion and village pubs in northern England: An econometric study. Regional Studies, 50(7): 1203-1216.

Nason, R. S., Bacq, S., \& Gras, D. 2018. A behavioral theory of social performance: Social identity and stakeholder expectations. Academy of Management Review, 43(2): 259-283.

Navis, C., \& Glynn, M. A. 2011. Legitimate distinctiveness and the entrepreneurial identity: Influence on investor judgments of new venture plausibility. Academy of Management Review, 36(3): 479-499.

Olson, M. 1965. The logic of collective action. Cambridge, MA: Harvard University Press.

Ostrom, E. 1999. Collective action and the evolution of social norms. Journal of Natural Resources Policy Research, 6(4): 235-252.

Patton, M. Q. 1990. Qualitative Evaluation and Research Methods, Beverly Hills, CA: Sage.

Pearce, J. L. 1980. Apathy or self interest? The vollinteer's avoidance of leadership roles. Journal of Voluntary Action Research, 9(1-4): 85-94.

Peredo, A. M., \& Chrisman, J. J. 2017. Conceptual foundations: Community-based enterprise and community development. In M.van Ham, D. Reuschke, R. Kleinhans, C. Mason, \& S. Syrett (Eds.), Entrepreneurial Neighbourhoods: Towards an Understanding of the Economies of Neighbourhoods and Communities: 151-172. Cheltenham, UK: Edward Elgar Publishing.

Peredo, A. M., \& Chrisman, J. J. 2006. Toward a theory of community-based enterprise. Academy of Management Review, 31(2): 309-328.

Plunkett Foundation. 2017. Community shops. Retrieved from https:/plunkett.co.uk/ community-shops. Accessed January 29, 2019.

Poteete, A. R., Janssen, M. A., \& Ostrom, E. 2010. Working together: Collective action, the commons, and multiple methods in practice. Princeton, NJ: Princeton University Press.

Powell, E. E., Hamann, R., Bitzer, V., \& Baker, T. 2018. Bringing the elephant into the room? Enacting conflict in collective prosocial organizing. Journal of Business Venturing, 33(5): 623-642.

Pratt, M. G. 2000. The good, the bad, and the ambivalent: Managing identification among Amway distributors. Administrative Science Quarterly, 45(3): 456-493.

Rao, H., \& Greve, H. R. 2018. Disasters and community resilience: Spanish flu and the formation of retail cooperatives in Norway. Academy of Management Journal, 61(1): 5-25.

Rao, H., Yue, L. Q., \& Ingram, P. 2011. Laws of attraction: Regulatory arbitrage in the face of activism in right-to-work states. American Sociological Review, 76(3): 365-385.

Ravasi, D., \& Schultz, M. 2006. Responding to organizational identity threats: Exploring the role of organizational culture. Academy of Management Journal, 49(3): 433-458.

Renko, M. 2013. Early challenges of nascent social entrepreneurs. Entrepreneurship Theory and Practice, 37(5): 1045-1069.

Romanelli, E., \& Khessina, O. M. 2005. Regional industrial identity: Cluster configurations and economic development. Organization Science, 16(4): 344-358.

Ross, M. H. 2007. Cultural contestation in ethnic conflict. Cambridge, MA: Cambridge University Press.

Sarasvathy, S., \& Ramesh, A. 2019. An effectual model of collective action for addressing sustainability challenges. Academy of Management Perspectives, 33(4): 405-424.

Seelos, C., Mair, J., Battilana, J., \& Dacin, M. T. 2011. The embeddedness of social entrepreneurship: Understanding variation across local communities. In C. Marquis, M. Lounsbury, \& R. Greenwood (Eds.), Communities and organizations: Research in the sociology of organizations, vol. 33: 333-363. Bingley, UK: Emerald Group Publishing Limited.

Selsky, J. W., \& Smith, A. E. 1994. Community entrepreneurship: A framework for social change leadership. The Leadership Quarterly, 5(2): 277-296.

Shepherd, D. A., \& Patzelt, H. 2017. Trailblazing in entrepreneurship: Creating new paths for understanding the field. New York: Springer

Shepherd, D. A. 2015. Party On! A call for entrepreneurship research that is more interactive, activity based, cognitively hot, compassionate, and prosocial. Journal of Business Venturing, 30(4): 489-507.

Short, J. C., Ketchen Jr, D. J., McKenny, A. F., Allison, T. H., \& Ireland, R. D. 2017. Research on crowdfunding: Reviewing the (very recent) past and celebrating the 
present. Entrepreneurship Theory and Practice, 41(2): 149-160.

Snow, D. A., \& McAdam, D. 2000. Identity work processes in the context of social movements: Clarifying the identity/movement nexus. In S. Stryker, T. Owens, \& R. White (Eds.), Self, identity and social movements: 51-64. Minneapolis, MN: University of Minnesota Press.

Somerville, P., \& McElwee, G. 2011. Situating community enterprise: A theoretical exploration. Entrepreneurship \& Regional Development, 23(5-6): 317-330.

Stern, H. 2018. Das sterben der dorfläden. Augsburger allgemeine. Retrieved from https://www.augsburgerallgemeine.de/bayern/Das-Sterben-der-Dorflaedenid44137936.html. Accessed January 29, 2019.

Stets, J. E., \& Burke, P. J. 2000. Identity theory and social identity theory. Social Psychology Quarterly, 63(3): 224-237.

Stryker, S., Owens, T., \& White, R. 2000. Self, identity and social movements. Minneapolis, MN: University of Minnesota Press.

Stryker, S. 2000. Identity competition: Key to differential social movement participation? In S. Stryker, T. Owens, \& R. White (Eds.), Self, identity and social movements: 21-40. Minneapolis, MN: University of Minnesota Press.

Tajfel, H. 1982. Social psychology of intergroup relations. Annual Review of Psychology, 33: 1-39.

Tajfel, H. 1974. Social identity and intergroup behaviour. Information (International Social Science Council), 13(2): 65-93.

Tajfel, H., \& Turner, J. C. 1979. An integrative theory of intergroup conflict. In W. G. Austin, \& S. Worchel (Eds.), The social psychology of intergroup relations: 33-47. Monterey, CA: Brooks/Cole.

Timmermans, S., \& Tavory, I. 2012. Theory construction in qualitative research: From grounded theory to abductive analysis. Sociological Theory, 30(3): 167-186.

Tolman, E. C. 1943. Identification and the postwar world. The Journal of Abnormal and Social Psychology, 38(2): 141-148.

UNDP Environment and Energy Group. 2010. The local capacity strategy: Enabling action for the environment and sustainable development. Retrieved from https://www.undp.org/content/dam/aplaws/publication/ en/publications/environment-energy/www-ee-library/ local-development/undps-local-capacity-strategy/Local \%20Capacity\%20Strategy\%20-\%20Final.pdf. Accessed January 29, 2019.

UNDP. 2018. Annual report 2017. Retrieved from https:// annualreport.undp.org/. Accessed January 29, 2019.

United Nations. 2015. Transforming our world: The 2030 agenda for sustainable development. A/RES/70/1. Retrieved from https://sustainabledevelopment.un.org/ post2015/transformingourworld. Accessed January 29, 2019.

Valchovska, S., \& Watts, G. 2016. Interpreting communitybased enterprise: A case study from rural Wales. Journal of Social Entrepreneurship, 7(2): 211-235.

van der Vegt, G. S., Essens, P., Wahlström, M., \& George, G. 2015. Managing risk and resilience. Academy of Management Journal, 58(4): 971-980.

van Knippenberg, A. D. 1984. Intergroup differences in group perceptions. In H. Tajfel (Ed.), The social dimension: European developments in social psychology, vol. 2: 560-578. Cambridge, MA: Cambridge University Press.

Vega, D. E. C., \& Keenan, R. J. 2016. Situating community forestry enterprises within New Institutional Economic theory: What are the implications for their organization? Journal of Forest Economics, 25(1): 1-13.

Vestrum, I., Rasmussen, E., \& Carter, S. 2017. How nascent community enterprises build legitimacy in internal and external environments. Regional Studies, 51(11): 1721-1734.

Vestrum, I., \& Rasmussen, E. 2013. How community ventures mobilise resources: Developing resource dependence and embeddedness. International Journal of Entrepreneurial Behavior \& Research, 19(3): 283-302.

Vestrum, I. 2016. Integrating multiple theoretical approaches to explore the resource mobilization process of community ventures. Journal of Enterprising Communities: People and Places in the Global Economy, 10(1): 123-134.

Vestrum, I. 2014. The embedding process of community ventures: Creating a music festival in a rural community. Entrepreneurship \& Regional Development, 26(7-8): 619-644.

White, R. W., \& Fraser, M. R. 2000. Personal and collective identities and long-term social movement activism. In S. Stryker, T. J. Owens, \& R. W. White (Eds.), Self, identity and social movements: 324-346. Minneapolis, MN: University of Minnesota Press.

Williams, T. A., \& Shepherd, D. A. 2016. Building resilience or providing sustenance: Different paths of emergent ventures in the aftermath of the Haiti earthquake. Academy of Management Journal, 59(6): 2069-2102.

Yin, R. K. 2013. Case study research: Design and methods. London: Sage.

\section{$M$}

Christina Hertel (christina.hertel@epfl.ch) is a postdoctoral research associate at the Chair of Entrepreneurship and Technology Commercialization at École Polytechnique Fédérale de Lausanne. She received her $\mathrm{PhD}$ in 
management from the Technical University of Munich. Her research focuses on collective forms of entrepreneurship and identity dynamics in and around organizations. https://www.christinahertel.com

Sophie Bacq (bacqs@iu.edu) is an associate professor of entrepreneurship at Indiana University Kelley School of Business. She received her PhD in management from the Université catholique de Louvain. Her research centers on social entrepreneurship, societal impact, and the governance of hybrid organizations. She is the codirector of the Annual Social Entrepreneurship Conference. https://kelley.iu.edu/faculty-research/faculty-directory/ profile.cshtml?id=BACQS

Frank-Martin Belz (frank.belz@tum.de) is full professor for corporate sustainability at the Technical University of Munich (TUM School of Management). He received his $\mathrm{PhD}$ in management from the University of St. Gallen. His research focuses on sustainable entrepreneurship in the Global North and the Global South. https://www. sustainability.wi.tum.de/en/chair/holder/ 
Copyright of Academy of Management Discoveries is the property of Academy of Management and its content may not be copied or emailed to multiple sites or posted to a listserv without the copyright holder's express written permission. However, users may print, download, or email articles for individual use. 